OPEN ACCESS

Edited by:

Anjan Debnath,

University of California, San Diego,

USA

Reviewed by:

Yuji Morita,

Aichi Gakuin University, Japan

Upinder Singh,

Stanford University, USA

*Correspondence:

Tomoyoshi Nozaki,

Department of Parasitology, National

Institute of Infectious Diseases,

Toyama 1-23-1, Shinjuku-ku, Tokyo

162-8640, Japan

nozaki@nih.go.jp

${ }^{\dagger}$ Present Address:

Gil M. Penuliar,

Institute of Biology, College of

Science, University of the Philippines,

Quezon City, Philippines

Specialty section:

This article was submitted to

Antimicrobials, Resistance and

Chemotherapy,

a section of the journal

Frontiers in Microbiology

Received: 13 February 2015 Accepted: 08 April 2015

Published: 05 May 2015

Citation:

Penuliar GM, Nakada-Tsukui $K$ and

Nozaki T (2015) Phenotypic and transcriptional profiling in Entamoeba histolytica reveal costs to fitness and adaptive responses associated with metronidazole resistance.

Front. Microbiol. 6:354.

doi: 10.3389/fmicb.2015.00354

\section{Phenotypic and transcriptional profiling in Entamoeba histolytica reveal costs to fitness and adaptive responses associated with metronidazole resistance}

\author{
Gil M. Penuliar ${ }^{1,2 \dagger}$, Kumiko Nakada-Tsukui ${ }^{1}$ and Tomoyoshi Nozaki ${ }^{1,3 *}$
}

\begin{abstract}
${ }^{1}$ Department of Parasitology, National Institute of Infectious Diseases, Tokyo, Japan, ${ }^{2}$ Department of Parasitology, Gunma University Graduate School of Medicine, Maebashi, Japan, ${ }^{3}$ Graduate School of Life and Environmental Sciences, University of Tsukuba, Tsukuba, Japan
\end{abstract}

Antimicrobial chemotherapy is critical in the fight against infectious diseases caused by Entamoeba histolytica. Among the drugs available for the treatment of amebiasis, metronidazole (MTZ) is considered the drug of choice. Recently, in vitro studies have described MTZ resistance and the potential mechanisms involved. Costs to fitness and adaptive responses associated with resistance, however, have not been investigated. In this study we generated an $\mathrm{HM}-1$ derived strain resistant to $12 \mu \mathrm{M}$ MTZ (MTZR). We examined its phenotypic and transcriptional profile to determine the consequences and mRNA level changes associated with MTZ resistance. Our results indicated increased cell size and granularity, and decreased rates in cell division, adhesion, phagocytosis, cytopathogenicity, and glucose consumption. Transcriptome analysis revealed 142 differentially expressed genes in MTZR. In contrast to other MTZ resistant parasites, MTZR did not down-regulate pyruvate:ferredoxin oxidoreductase, but showed increased expression of genes for a hypothetical protein (HP1) and several iron-sulfur flavoproteins, and downregulation of genes for leucine-rich proteins. Fisher's exact test showed 24 significantly enriched GO terms in MTZR, and a 3-way comparison of modulated genes in MTZR against those of MTZR cultured without MTZ and HM-1 cultured with MTZ, showed that 88 genes were specific to MTZR. Overall, our findings suggested that MTZ resistance is associated with specific transcriptional changes and decreased parasite virulence.

Keywords: Entamoeba histolytica, metronidazole, drug resistance, transcriptome

\section{Introduction}

Currently, 500 million cases of amebiasis are reported each year (World Health Organization Amoebiasis, 1997). Most of these cases are children from developing nations, who are particularly vulnerable to infectious diseases (Marie and Petri, 2014). Among the drugs available for the treatment of amebic dysentery and amebic liver abscess, metronidazole (MTZ) is one of the most widely used, and is often considered the drug of choice (Löfmark et al., 2010). Treatment with MTZ is usually very effective, i.e., no clinical isolates with high levels of resistance have been observed. 
However, reports of patients refractory to the drug are documented (Koutsaimanis et al., 1979; Dooley and O'Morain, 1988). In addition, in vitro studies on the induction of MTZ resistance in Entamoeba histolytica are described (Samarawickrema et al., 1997; Wassmann et al., 1999). Coincidentally, clinical and in vitro resistance to the drug in Trichomonas vaginalis (Müller et al., 1980; Wright et al., 2010), Giardia lamblia (Müller et al., 2007; Tejman-Yarden et al., 2011), Blastocystis spp. (Mirza et al., 2011a,b), Neisseria gonorrhoeae (Yoshikawa et al., 1974), and several anaerobic bacteria (Pumbwe et al., 2007; Peláez et al., 2008; Tanih et al., 2011) have also been reported since the drug was introduced in 1960 (Figure S1) (Durel et al., 1960). Based on these findings, it is reasonable to assume that clinical resistance to MTZ might soon be reported in E. histolytica.

Unlike aerobic cells, anaerobic organisms are sensitive to MTZ because their electron transport proteins have sufficient negative redox potential that can activate MTZ (Samuelson, 1999). After entering the cell, the drug is reduced to a cytotoxic nitro radical anion by electron donors like thioredoxin reductase and ferredoxin $(\mathrm{Fdx})$, which in turn serve as electron acceptors for pyruvate:ferredoxin oxidoreductase (PFOR) (Samuelson, 1999; Leitsch et al., 2007). The nitro radical anion is reduced further to a nitrosoimidazole, and further reduction leads to the formation of hydroxylamine and eventually to an amine (West et al., 1982; Moreno and Docampo, 1985; Ludlum et al., 1988). In E. histolytica, the actual mechanism of action is not fully understood, but evidences from other organisms suggest inhibition of DNA synthesis, and damage to DNA, protein, and other cell components by oxidation and adduct formation (Ludlum et al., 1988; Sisson et al., 2000; Leitsch et al., 2007).

A few mechanisms have been proposed to explain how pathogens survive MTZ treatment. The process varies among organisms, but the general principle includes at least one of the following: altered reduction efficiency (Leiros et al., 2004), drug inactivation (Ralph and Clarke, 1978), reduced drug uptake (Lacey et al., 1993), active efflux (Pumbwe et al., 2007), and increased DNA damage repair (Land and Johnson, 1999). In E. histolytica, Samarawickrema et al. (1997) reported the increased expression of iron-containing superoxide dismutase (Fe-SOD) in a strain resistant to $10 \mu \mathrm{M}$ MTZ, while Wassmann et al. (1999) showed that in addition to $\mathrm{Fe}-\mathrm{SOD}$ upregulation, resistance to $40 \mu \mathrm{M}$ MTZ was associated with increased peroxiredoxin (Prx) expression and decreased expression of Fdx. On the contrary, Tazreiter et al. (2008) showed no substantial increase in Fe-SOD expression and less than 3-fold upregulation of Fdx and Prx in cells exposed to $50 \mu \mathrm{M}$ MTZ. In addition, all three studies did not find any significant changes in PFOR expression, indicating that its downregulation may not be mandatory for low to modest drug resistance in this parasite. Studies on MTZ resistance in $T$. vaginalis and $G$. lamblia also showed variable results regarding the role of PFOR (Quon et al., 1992; Rasoloson et al., 2002; Müller et al., 2008; Leitsch et al., 2011). Strains of T. vaginalis deficient in PFOR activity, for example, showed only low levels of anaerobic resistance to MTZ (Rasoloson et al., 2002). In addition, some clinical strains exhibited resistance only under aerobic conditions, and were completely sensitive to MTZ in the absence of oxygen (Rasoloson et al., 2002). These strains also showed no decrease in PFOR activity (Rasoloson et al., 2002). Other reports, however, have shown decreased Fdx levels in MTZ resistant trichomonads (Ralph et al., 1974; Yarlett et al., 1986) and anaerobic resistance that was correlated with decreased PFOR activity (Kulda et al., 1989). From these results, it is conceivable that different pathways are involved in drug activation, and that various mechanisms for MTZ resistance exist in protozoa.

Currently, most of the work done in E. histolytica focused either on pathways known to activate, i.e., chemically reduce, MTZ (Leitsch et al., 2007) or antioxidants that counteract oxidative stress, such as pyruvate:ferredoxin oxidoreductase, superoxide dismutase, and peroxiredoxin (Samarawickrema et al., 1997; Wassmann et al., 1999). Fitness costs and adaptive responses have not yet been examined. In this study we generated an E. histolytica HM-1-derived isogenic strain resistant to $12 \mu \mathrm{M}$ MTZ (MTZR). By comparing its phenotype and transcriptional profile against the parental strain, our goal was to identify phenotypic and transcriptional changes related to or involved in MTZ resistance. We compared the transcriptome of a single MTZR line cultured with MTZ [MTZR (+)] against MTZR cultured without the drug [MTZR $(-)]$, and HM-1 exposed to MTZ [HM-1 (+)] to determine the significance of the genes we identified. Finally, to verify their involvement in resistance, some genes were overexpressed by episomal transfection, followed by drug challenge.

\section{Materials and Methods}

\section{Chemicals and Reagents}

MTZ, ornidazole, emetine, chloroquine, paromomycin, Lcysteine, and N-(trans-Epoxysuccinyl)-L-leucine 4-guanidinobut ylamide (E-64) were purchased from Sigma-Aldrich (St. Louis, MO, USA), while tinidazole was acquired from LTK Laboratories (St. Paul, MN, USA). DNAzol reagent, TRIzol reagent, PLUS reagent, Lipofectamine, and geneticin (G418) were secured from Invitrogen (Carlsbad, CA, USA). All other chemicals were obtained from Wako Pure Chemical Industries (Osaka, Japan) unless otherwise stated. Drugs were dissolved either in distilled water or dimethyl sulfoxide (DMSO) to a stock concentration of $100 \mathrm{mM}$ and stored at $-30^{\circ} \mathrm{C}$.

\section{Cultivation and Induction of MTZ Resistance}

E. histolytica strain HM-1:IMSS cl6 (HM-1) (Diamond et al., 1972) was cultured under axenic conditions in $6 \mathrm{~mL}$ BI-S-33 medium (BIS) at $35.5^{\circ} \mathrm{C}$ in $13 \times 100 \mathrm{~mm}$ Pyrex screw cap culture tubes (Corning, Corning, NY) (Diamond et al., 1978). Induction of MTZ resistance was initiated when cells in mid-logarithmic phase of growth were exposed to $1 \mu \mathrm{M}$ of the drug until late logarithmic phase. In this study, cultures with cell concentrations between $4 \times 10^{4}$ and $2 \times 10^{5} / \mathrm{mL}$ were considered to be in mid-logarithmic phase, and corresponds to cell densities after 1 and 2 days, respectively, after the cultures were initiated with at $2-5 \times 10^{4}$ trophozoites per $\mathrm{mL}$. The drug concentration was increased by $1 \mu \mathrm{M}$ until it reached $4 \mu \mathrm{M}$. Cells were maintained with the same dose for 4 weeks before further increase in drug concentration was made. A strain growing at $12 \mu \mathrm{M} \mathrm{MTZ}$ 
[MTZR (+)] was obtained approximately after 28 weeks, and was used in all experiments. MTZR was also cultured without the drug [MTZR $(-)$ ] for $24 \mathrm{~h}$ up to 1 week when we tested for reversibility of resistance and when samples were prepared for microarray.

\section{Cultivation of Chinese Hamster Ovary (CHO) Cells}

CHO cells, a gift from Dr. Kentaro Hanada, were cultured in Ham's F-12 medium (GIBCO, Invitrogen Co., Auckland, New Zealand) with $10 \%$ fetal calf serum (Medical Biological Laboratory International, Woburn, MA, USA) in $25 \mathrm{~cm}^{2}$ canted neck culture flasks (IWAKI, Tokyo, Japan) at $37^{\circ} \mathrm{C}$ with humidified air and $5 \% \mathrm{CO}_{2}$.

\section{Growth Kinetics}

After trophozoite cultures in mid-log phase of HM-1 and MTZR were placed on ice for $5 \mathrm{~min}$ to detach cells from the glass surface, cells were collected by centrifugation $500 \times \mathrm{g}$ for $5 \mathrm{~min}$ at room temperature. After centrifugation, spent medium was discarded and the pellet was resuspended in 1-2 $\mathrm{mL}$ of BIS medium. The cell number was estimated on a haemocytometer. Approximately $6 \times 10^{4}$ trophozoites were inoculated in $6 \mathrm{~mL}$ BIS medium with or without $12 \mu \mathrm{M} \mathrm{MTZ}$, and the cultures were examined every $24 \mathrm{~h}$ for 5 days. Trypan blue exclusion assay was used to determine the number of viable cells in duplicate cultures (Penuliar et al., 2011).

\section{Half Maximal Inhibitory Concentration $\left(\mathrm{IC}_{50}\right)$ and Cross-Resistance}

Trophozoites in mid-log phase of HM-1 and MTZR were harvested, resuspended in BIS medium as described above, and the concentration was adjusted to $1 \times 10^{5}$ cells $/ \mathrm{mL}$. About $1 \times 10^{4}$ cells in $100 \mu \mathrm{L}$ BIS were seeded per well of a 96-well microtiter plate (Iwaki, Tokyo, Japan) and incubated at $35.5^{\circ} \mathrm{C}$ for $1 \mathrm{~h}$ under anaerobic conditions using Anaerocult A (Merck, Darmstadt, Germany). One hundred microliters of BIS containing 2-fold increases in concentration of the drugs listed in Table 1 was added, and the plates incubated for 24 and $48 \mathrm{~h}$. The medium was removed and replaced with $200 \mu \mathrm{L} 10 \%$ WST-1 reagent (Roche, Indianapolis, IN, USA) in phosphate-buffered saline (PBS) and the plates incubated for 20-40 min. Optical density at $450 \mathrm{~nm}$ was measured using a DTX 880 Multimode Detector (Beckman Coulter, Fullerton, CA, USA). The percentage of viable cells was calculated after subtraction of background absorbance as $\%$ viability $=$ (absorbance of treated cells/absorbance of untreated cells $) \times 100 \%$. IC 50 values were calculated using the sigmoidal dose-response equation in GraphPad Prism 5.0 (GraphPad Software, La Jolla, CA, USA). All experiments were repeated three times with two replicates per experiment. To assay the hydrogen peroxide sensitivity of the transformants harboring one of the following plasmids: HP1-HA, ISF1-HA, ISF2-HA, ISF4-HA, and pEhEx-HA, about $1 \times 10^{4}$ cells were seeded per well of a 96 -well microtiter plate and incubated at $35.5^{\circ} \mathrm{C}$ for $12-$ $16 \mathrm{~h}$ under anaerobic conditions. The cells were then exposed to $25-1600 \mu \mathrm{M}$ of hydrogen peroxide for $4 \mathrm{~h}$. Then the cell viability was measured by using WST-1 reagent as described above.
TABLE $1 \mid I_{50}$ of drugs used to treat amebiasis and hydrogen peroxide in HM-1 and MTZR.

\begin{tabular}{llrrr}
\hline Compound & Description & HM-1 & MTZR & $\mathbf{R I}^{\mathbf{a}}$ \\
\hline Chloroquine & Amebicide & $1562.7 \pm 0.3$ & $3125.3 \pm 0.4$ & 2.0 \\
Emetine & Amebicide & $12.8 \pm 0.3$ & $50.3 \pm 0.3$ & 3.9 \\
Metronidazole & Amebicide & $6.5 \pm 0.3$ & $12.9 \pm 0.3$ & 2.0 \\
Ornidazole & Amebicide & $6.5 \pm 0.3$ & $12.3 \pm 0.3$ & 1.9 \\
Paromomycin & Amebcide & $12.6 \pm 0.4$ & $25.1 \pm 0.3$ & 2.0 \\
Tinidazole & Amebicide & $12.6 \pm 0.2$ & $24.9 \pm 0.3$ & 2.0 \\
Hydrogen peroxide & Stress inducer & $244.2 \pm 0.4$ & $488.1 \pm 0.3$ & 2.0
\end{tabular}

${ }^{a}$ Resistance index values are determined by dividing the $/ C_{50}$ of drug in MTZR by that in HM-1.

\section{CHO Monolayer Destruction Assay}

Rate of $\mathrm{CHO}$ monolayer destruction was measured as described previously with minor modifications (Penuliar et al., 2011). Briefly, CHO cells in logarithmic phase of growth were prepared as follows. After spent medium was discarded, $\mathrm{CHO}$ cells were incubated with trypsin-EDTA at $37^{\circ} \mathrm{C}$ for $5 \mathrm{~min}$ to detach cells. Cells were transferred to a $50 \mathrm{~mL}$ tube containing $5 \mathrm{~mL}$ of Ham's F-12 medium and cell density was estimated on a haemocytometer. Cells were collected by centrifugation at 500 $\times \mathrm{g}$ for $10 \mathrm{~min}$ at room temperature. After the supernatant was discarded, the cell pellet was re-suspended in Ham's F-12 medium at $1 \times 10^{5} \mathrm{CHO}$ cells per $\mathrm{mL}$. Approximately $100 \mu \mathrm{L}$ of the $\mathrm{CHO}$ suspension was dispensed into each well on a 96-well plate and the plate was incubated at $37^{\circ} \mathrm{C}$ as described (Penuliar et al., 2011) for 24-48 h until CHO cells form a monolayer. The medium was removed and the plates washed twice with warm PBS. Approximately $1 \times 10^{4}$ cells of HM-1 and MTZR were resuspended in $200 \mu \mathrm{L}$ Opti-MEM medium (GIBCO, Invitrogen Co., Auckland, New Zealand) and added to each well. The plates were incubated under anaerobic conditions at $35.5^{\circ} \mathrm{C}$ for $15 \mathrm{~min}$ intervals up to $2 \mathrm{~h}$. The plates were placed on ice for $15 \mathrm{~min}$ to release adhered trophozoites and washed twice with cold PBS. The percentage of $\mathrm{CHO}$ monolayer destroyed was determined relative to wells without the ameba using $10 \%$ WST-1.

\section{Substrate Gel Electrophoresis}

Proteinase activity was detected by substrate gel electrophoresis as described previously (Hellberg et al., 2000). Briefly, $20 \mu \mathrm{g}$ of cell lysate from HM-1 and MTZR strains were separated in a $12 \%[\mathrm{w} / \mathrm{v}]$ sodium dodecyl sulfate (SDS)-polyacrylamide gel copolymerized with $0.1 \%[\mathrm{w} / \mathrm{v}]$ gelatin. The gel was incubated in $2.5 \%[\mathrm{v} / \mathrm{v}]$ Triton $\mathrm{X}-100$ for $1 \mathrm{~h}$ and then in $100 \mathrm{mM}$ sodium acetate, $\mathrm{pH} 4.5,1 \%[\mathrm{v} / \mathrm{v}]$ Triton X-100, and $20 \mathrm{mM}$ dithiothreitol for $3 \mathrm{~h}$ at $37^{\circ} \mathrm{C}$. Bands were visualized after staining with $0.5 \%$ [w/v] Coomassie Brilliant Blue R-250.

\section{Phagocytosis Assay}

Trophozoites of HM-1 and MTZR in mid-logarithmic phase of growth were harvested, resuspended in BIS medium as described above, and the concentration was adjusted to $1 \times 10^{6}$ cells $/ \mathrm{mL}$. Approximately $1.0 \times 10^{6}$ of HM-1 and MTZR trophozoites 
were seeded on each well of 12 -well plates. Spent medium was removed and replaced with $500 \mu \mathrm{L}$ warmed BIS with $1.5 \times 10^{7}$ FluoSpheres carboxylate-modified $(2.0 \mu \mathrm{m})$ Nile Red fluorescent beads (Invitrogen, Eugene, OR, USA). The plates were sealed and incubated at $35.5^{\circ} \mathrm{C}$ for up to $80 \mathrm{~min}$. After incubation, $500 \mu \mathrm{L}$ of PBS containing $2 \%$ galactose was added and the plates incubated on ice for at least $20 \mathrm{~min}$. Formaldehyde was added to a final concentration of $4 \%$ and plates incubated on ice for $1 \mathrm{~h}$. The cells were collected, washed three times with cold PBS and analyzed by flow cytometry as previously described (Nakada-Tsukui et al., 2005). Cells that ingested the beads were gated based on increased fluorescence compared to control non-phagocytic cells.

\section{Glucose Consumption}

Trophozoites of HM-1 and MTZR in mid-logarithmic phase of growth were harvested, resuspended in BIS medium as described above, and the concentration was adjusted to $1 \times 10^{7}$ cells $/ \mathrm{mL}$. Approximately $1 \times 10^{7}$ cells were seeded in 6-well dishes and incubated for 12 and $24 \mathrm{~h}$. Spent medium was decanted and centrifuged at $500 \times \mathrm{g}$ for $5 \mathrm{~min}$. Glucose consumption was determined from the clarified medium using a Glucose (GO) Assay kit (Sigma Aldrich, Saint Louis, MO, USA) according to manufacturer's protocol.

\section{Estimation of Total Protein Amount in a Single Cell}

Trophozoites of HM-1 and MTZR in mid-logarithmic phase of growth were harvested as described above. Cell pellet was resuspended in PBS at $1 \times 10^{6} / \mathrm{mL}$. Approximately $500 \mu \mathrm{L}$ of the cell suspension were dispensed to a $1.5 \mathrm{~mL}$ tube and the cells were collected by centrifugation at $500 \times \mathrm{g}$ for $3 \mathrm{~min}$ at $4^{\circ} \mathrm{C}$. After the supernatant was carefully removed, the cell pellet was lysed with $50 \mu \mathrm{L}$ of lysis buffer [50 mM Tris- $\mathrm{HCl}, \mathrm{pH} 7.5,150 \mathrm{mM} \mathrm{NaCl}$, $1 \%$ Triton-X 100, complete mini EDTA-free protease inhibitor cocktail (Roche Molecular Biochemicals, Mannheim, Germany) and $200 \mathrm{mM}$ E-64]. Protein amount of the lysate were quantified by $D C$ protein assay kit (Bio-Rad Laboratories, Inc., Hercules, CA, USA).

\section{RNA Isolation}

HM-1 and MTZR were cultured with and without $12 \mu \mathrm{M}$ MTZ in $25 \mathrm{~cm}^{2}$ tissue culture flasks. HM-1 cultured with the drug was incubated for $5 \mathrm{~h}[(\mathrm{HM}-1(+)]$, while MTZR without MTZ was maintained for 1 week [(MTZR $(-)]$. Except for HM-1 (+), the spent medium for all other cultures were removed and replaced with fresh BIS with and without the drug and the flasks incubated at $35.5^{\circ} \mathrm{C}$ for $5 \mathrm{~h}$. Total RNA was extracted with TRIzol Reagent according to the manufacturer's instructions for cells grown in monolayers; cleaned with RNeasy kit (Qiagen, Hilden, Germany), and assessed for quality with the Experion automated electrophoresis system and Experion RNA StdSens analysis kit (Bio-Rad Laboratories, Inc., Hercules, CA, USA). RNA quantity was determined by measuring the absorbance at $260 \mathrm{~nm}$ with NanoDrop ND-1000 UV-Vis spectrophotometer (NanoDrop Technologies, Wilmington, DE, USA).

\section{Microarray Hybridization}

Samples from two independent RNA extractions were processed using Ambion MessageAmpTM Premier RNA Amplification Kit (Applied Biosystems, Foster City, CA, USA) according to manufacturer's instructions. Fragmented cRNA was then hybridized onto a probe array chip (Eh_Eia520620F) that was custom-made by Affymetrix (Santa Clara, CA, USA) (Husain et al., 2011; Penuliar et al., 2012) using kits and protocols specified in the Affymetrix GeneChip Expression Analysis Technical Manual (Affymetrix, Santa Clara, CA, USA). Following hybridization, arrays were washed, stained with streptavidinphycoerythrin (Molecular Probes, Eugene, OR, USA) using Affymetrix GeneChip Fluidics Station 450, and scanned with an Affymetrix GeneChip Scanner 3000 at $570 \mathrm{~nm}$. Each array image was visually screened to check for scratches, signal artifacts, and debris.

The microarray used in this study was made based on E. histolytica and E. invadens sequences stored at TIGR and Pathema databases (Loftus et al., 2005; http://amoebadb.org/ amoeba/). It contained 9230 probe sets for E. histolytica and an additional 25 and 81 control probe sets for Entamoeba and Affymetrix, respectively (Eh_Eia520620F_Eh). Nomenclature for the IDs was based on whether the probe set is unique to either Pathema (e.g., EHI_123456) or TIGR (e.g., 12.m00345), or is found in both databases (e.g., 98.m00765_234567). Probe sets labeled with "_at" represent a single gene, while those labeled with “_s_at” represent probe sets that share all probes identically with at least two sequences. The “_s_at” probe sets represent highly similar transcripts, shorter forms of alternatively polyadenylated transcripts, or common regions in the $3^{\prime}$ ends of multiple alternative splice forms. Probe sets labeled with "_x_at," on the other hand, represent probe sets where it was not possible to select either a unique probe set or a probe set with identical probes among multiple transcripts. These probe sets could cross-hybridize with other genes in an unpredictable manner (Affymetrix, Santa Clara, CA, USA).

\section{Data Normalization, Analysis, and Deposition}

Raw probe intensities were generated by the GeneChip Operating Software (GCOS) and GeneTitan Instrument from Affymetrix. Resulting expression values were analyzed by R/BioConductor and GeneSpring GX Ver.11.5 to identify differentially expressed genes. Reproducibility of the experiments was determined by Pearson's correlation coefficient and confirmed by principal component analysis (Pearson, 1901; Stigler, 1989). Only genes that were considered "present" by GCOS in both arrays were used in further analysis. Gene probe sets were considered differentially expressed between samples if they had at least a 3 -fold change and a $P$-value $<0.05$, calculated using Welch's $t$-test (Welch, 1947), after multiple test correction by the Benjamini-Hochberg method (Benjamini and Hochberg, 1995). A post-hoc test using Tukey's Honestly Significant Difference test was conducted to determine significant differences between samples (Tukey, 1949). Probe sets ending with “_x_at” were removed together with redundant genes identified by sequence alignment using ClustalW2.48 Finally, RefSeq's annotated pseudogenes were omitted from 
the final list (ClustalW2; http://www.ebi.ac.uk/Tools/msa/ clustalw2/).

Nucleotide sequences of differentially expressed genes were searched against GenBank (http://www.ncbi.nlm.nih. gov/genbank/) and Amoeba DB (http://amoebadb.org/ amoeba/) by using Basic Local Alignment Search Tool (BLAST; http://blast.ncbi.nlm.nih.gov/Blast.cgi). Matches against hypothetical proteins (HP) with $E$-value $<\mathrm{e}^{-50}$ and maximal scoring pair alignment that covered at least $40 \%$ were considered as putative orthologs (McLysaght et al., 2003). Hierarchical clustering of modulated genes in MTZR, MTZR (-), and HM-1 (+) was performed with Cluster 3.0 (http://bonsai.hgc.jp/ mdehoon/software/cluster/software.htm) using average linkage, while dendrograms and heatmaps were generated with Java TreeView version 1.1.6r2. (http:// jtreeview.sourceforge.net) Gene Ontology (GO) annotations were mined from the Gene Ontology Annotation Database (http://www.ebi.ac.uk), and Amoeba DB. GO term enrichment was computed using Fisher's exact test (Agresti, 1992), against a background consisting of all GO IDs for genes symbols beginning with EHI, which were downloaded from the QuickGO database of European Molecular Biology Laboratory - European Bioinformatics Institute (EMBL-EBI) (Taxon ID: 5759) (http:// www.ebi.ac.uk/QuickGO/). Genomic location of each gene was obtained from Pathema-Entamoeba (http://pathema.jcvi.org) while transmembrane domain prediction was performed using the following online servers: HMMTOP (http://www.enzim. hu), SOSUI (http://bp.nuap.nagoya-u.ac.jp), TMHMM (http:// www.cbs.dtu.dk), TopPred (http://mobyle.pasteur.fr), TMpred (http://www.ch.embnet.org), and Phobius (http://phobius.sbc. su.se). Signal peptide sequences were predicted using SignalP (http://www.cbs.dtu.dk), SOSUIsignal (http://bp.nuap.nagoya-u. ac.jp), and Phobius. Putative transmembrane domains and signal peptides were considered present only if positive hits were found in all programs used. Venn diagrams were constructed using Venn Diagram Generator (http://www.pangloss.com/seidel/ Protocols/venn.cgi).

The microarray data reported in this paper has been deposited in the Gene Expression Omnibus (GEO) database (http://www. ncbi.nlm.nih.gov/geo/) with accession number GSE35990.

\section{Generation of Transgenic Ameba Overexpressing HP1 and ISFs}

Full-length gene sequences were amplified from MTZR cDNA with sense- and anti-sense primers containing appropriate restriction sites (Table S2). PCR primers were designed as follows: sense primers contained 26 30 nucleotides corresponding to a region of each gene encoding the amino-terminal portion of each target proteins, fused at the $5^{\prime}$ end with three additional nucleotides and SmaI restriction enzyme recognition site (tccCCCGGG); reverse primers contained 22 33 nucleotides corresponding to a region of each gene encoding the carboxylterminal portion of each target proteins, fused at the $5^{\prime}$ end with three additional nucleotides and XhoI restriction enzyme recognition site (ccgCTCGAG). PCR was performed with the cDNA as a template using a DNA Engine Peltier Thermal Cycler (Bio-Rad, Hercules, CA, USA). The PCR cycling conditions consisted of an initial step of denaturation at $94^{\circ} \mathrm{C}$ for $1 \mathrm{~min}$, followed by 30 cycles of denaturation at $98^{\circ} \mathrm{C}$ for $10 \mathrm{~s}$, annealing at $55^{\circ} \mathrm{C}$ for $30 \mathrm{~s}$, and extension at $72^{\circ} \mathrm{C}$ for $60 \mathrm{~s}$ with Phusion DNA polymerase (New England BioLabs, Tokyo, Japan). Resultant PCR fragments were precipitated with ethanol, digested with appropriate restriction enzymes, and then purified from an exised piece of agarose gel by using GENECLEAN kit (Funakoshi, Tokyo, Japan). After purification, the gene was inserted into an expression plasmid, pEhEx, as previously described (Penuliar et al., 2012). The plasmid was introduced into E. histolytica G3 strain by lipofection, with minor modifications as previously described (Penuliar et al., 2012). Briefly, E. histolytica G3 trophozoites in the mid- logarithmic growth phase were harvested as described above, and re-suspended with Opti-MEM medium supplemented with $5 \mathrm{mg} / \mathrm{mL} \mathrm{L}$-cysteine and $1 \mathrm{mg} / \mathrm{mL}$ ascorbic acid at $1 \times 10^{5}$ cells $/ \mathrm{mL}$. Approximately $5 \mathrm{~mL}$ of the suspension was dispensed into each well on a 12 -well plate and the plate was incubated under anaerobic condition at $35.5^{\circ} \mathrm{C}$ for $30 \mathrm{~min}$. Following incubation, $4.5 \mathrm{~mL}$ medium from each well was removed and $500 \mu \mathrm{L}$ liposome-plasmid-mixture $(5 \mu \mathrm{g}$ plasmid, $10 \mu \mathrm{L}$ PLUS reagent, $20 \mu \mathrm{L}$ Lipofectamine in OptiMEM medium) was added. After $5 \mathrm{~h}$ of transfection, cells were harvested by placing the plate on ice for $15 \mathrm{~min}$, then added to culture tubes with $5.5 \mathrm{~mL}$ cold BIS, and incubated at $35.5^{\circ} \mathrm{C}$ for $24 \mathrm{~h}$. Transformants were initially selected in the presence of $1 \mu \mathrm{g} / \mathrm{mL}$ of $\mathrm{G} 418$, and drug concentration was gradually increased to $10 \mu \mathrm{g} / \mathrm{mL}$ during the following 6 weeks before the transformants were analyzed.

\section{Reverse Transcriptase (RT)-PCR and Quantitative Real-Time (qRT)-PCR}

Total RNA from semi-confluent cultures, about $2 \times 10^{5}$ cells $/ \mathrm{mL}$, of HM-1, MTZR, and transformants harboring one of the following plasmids: pEhEx-HA (mock plasmid), HP1-HA, ISF1$\mathrm{HA}$, ISF2-HA, and ISF4-HA, cultured in $25 \mathrm{~cm}^{2}$ flasks, was extracted and quantified as described previously (Penuliar et al., 2012). cDNA was reverse transcribed from $5 \mu \mathrm{g}$ RNA with the SuperScript III First-Strand Synthesis System, and RT-PCR was performed with the resulting $\mathrm{CDNA}$ as template and primers listed in Table S2 on a DNA Engine Peltier Thermal Cycle (Bio-Rad Laboratories, Inc., Hercules, CA, USA). The PCR parameters used were: an initial denaturation step at $95^{\circ} \mathrm{C}$ for $2 \mathrm{~min}$ followed by 30 cycles of denaturation at $94^{\circ} \mathrm{C}$ for $15 \mathrm{~s}$, annealing at $55^{\circ} \mathrm{C}$ for $30 \mathrm{~s}$, and extension at $72^{\circ} \mathrm{C}$ for 30 or $60 \mathrm{~s}$. The products were resolved on $1.5 \%[\mathrm{w} / \mathrm{v}]$ agarose gel with $0.5 \mu \mathrm{g} / \mathrm{mL}$ ethidium bromide, visualized, and photographed under ultraviolet illumination.

The Fast SYBR Green Master Mix (Applied Biosystems, Foster City, CA, USA) was used for qRT-PCR in accordance with the manufacturer's instructions. The list of primers for genes whose expression was quantified by qRT-PCR can be found in Table $\mathrm{S} 1$, and includes a housekeeping gene, RNA polymerase II gene (rpoII), as control. Each PCR reaction contained $5 \mu \mathrm{L}$ (1:50 dilution) of cDNA and $15 \mu \mathrm{L}$ primer mix, composed of $10 \mu \mathrm{L} 2 \mathrm{X}$ Fast SYBR Green Master Mix, sense and antisense primers, and nuclease-free water, to bring the volume to $20 \mu \mathrm{L}$. qRT-PCR was performed using StepOne Plus Real-Time PCR System (Applied 
Biosystems, Foster City, CA, USA) with the following cycling conditions: enzyme activation at $95^{\circ} \mathrm{C}$ for $20 \mathrm{~s}$, followed by 40 cycles of denaturation at $95^{\circ} \mathrm{C}$ for $3 \mathrm{~s}$ and annealing/extension at $60^{\circ} \mathrm{C}$ for $30 \mathrm{~s}$. All test samples were run in triplicate including an RT-negative control for each sample set along with a blank control consisting of nuclease-free water in place of cDNA. Quantification for each target gene was determined by the $\Delta \Delta \mathrm{Ct}$ method with rpoII as reference gene (Livak and Schmittgen, 2001).

\section{Statistical Analysis}

Correlation coefficients were calculated using the Student's $t$ test function of Microsoft Excel statistical package (Microsoft Corp., Redmond, WA, USA). Probability levels $(P)<0.05$ were considered significant.

\section{Results}

\section{Generation and Phenotypic Characterization of MTZR}

Exposure of HM-1 to MTZ concentrations up to $3 \mu \mathrm{M}$ for $24 \mathrm{~h}$ did not result in any significant changes in cell morphology. Cells continued to grow and cultures formed confluent lawns after $72 \mathrm{~h}$. Starting at $6 \mu \mathrm{M}$ MTZ, however, cells became rounder than usual and were slightly bigger in size. Cells also took longer to attach to surfaces and for cultures to form confluent lawns. Cell viability, however, was verified by cell adhesion and trypan blue exclusion assay. After 29 weeks, cells growing at $12 \mu \mathrm{M} \mathrm{MTZ}$ (MTZR) were obtained. We tried to increase the concentration of MTZ further, but this resulted in further increase in doubling time.

The population doubling time of MTZR was significantly longer compared to HM-1 (26.8 \pm 0.9 and $18.2 \pm 0.5 \mathrm{~h}$, respectively; $P$-value $<0.001$, Figure 1). MTZR also appeared rounder, bigger, and more granular than HM-1. In contrast, parental cells exposed to $12 \mu \mathrm{M}$ MTZ showed signs of morphological changes as early as $2 \mathrm{~h}$, rounding in $5 \mathrm{~h}$, cell shrinkage, and detachment within $24 \mathrm{~h}$. The slight enlargement of MTZR $(+)$ compared to HM-1 was suggested when we measured the total protein content of MTZR and HM-1, 4.81 \pm 0.04 and $4.24 \pm 0.03 \mathrm{pg} / \mathrm{cell}$, respectively. Flow cytometric analysis also confirmed that MTZR was slightly larger than HM-1 (data not shown).

The $\mathrm{IC}_{50}$ of MTZ in MTZR and HM-1 was $12.9 \pm 0.3$ and $6.5 \pm 0.3 \mu \mathrm{M}$, respectively, and its resistance index was 2.0 (Table 1). When MTZR was cultured without the drug for 1 week followed by MTZ challenge for $24 \mathrm{~h}$, percent survival was only $28 \%$, indicating that resistance to the drug was reversible (data not shown). To determine if MTZR was cross-resistant with other amebicides, the $\mathrm{IC}_{50}$ of the drugs listed in Table $\mathbf{1}$, against MTZR and HM-1 was determined. Results showed that MTZR had reduced sensitivity to the drugs.

MTZR had a slower rate of $\mathrm{CHO}$ monolayer destruction, especially at early time points, indicating a slight decrease in virulence ( $P$-value $<0.05$ for 30, 45, 60, and 75 min; Figure 2A). This was consistent with the observed decrease in intensity of bands corresponding to cysteine protease 1 and 2 (CP1 and

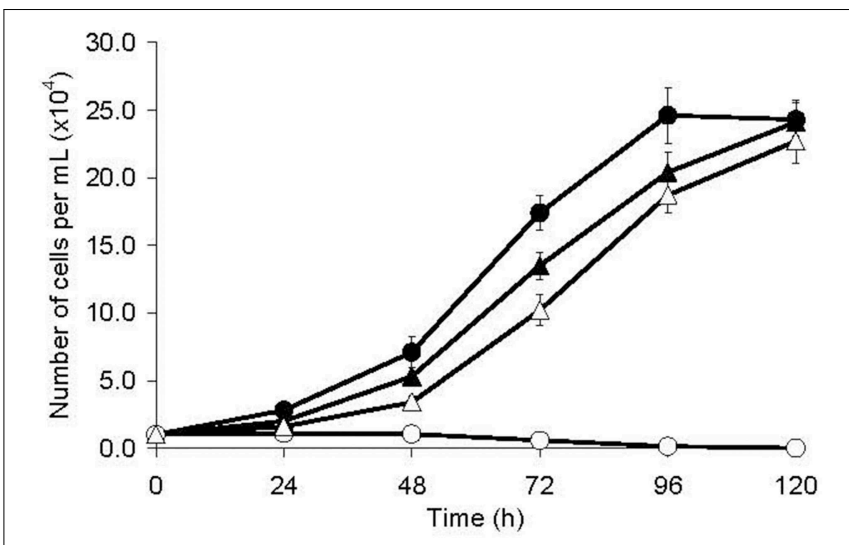

FIGURE 1 | Growth kinetics of HM-1 (circles) and MTZR (triangles) cultured with (open symbols) or without (filled symbols) $12 \mu \mathrm{M}$ MTZ.

$\mathrm{CP} 2$, synonymous to EhCP-A1 and EhCP-A2, respectively) in the zymogram (Figure 2B), and by an ImageJ (http://rsbweb. nih.gov/ij/) analysis of the same bands that indicated an approximately $33 \%$ decrease in band areas. The band for CP5 (EhCP-A5) and control bands (arrow head) were comparable between HM-1 and MTZR. The decrease in cytopathy in MTZR was also indicated by the lower the number of engulfed beads (Figure 2C) and percentage of cells with engulfed beads in the phagocytosis assay (Figure 2D). MTZR also consumed glucose at a reduced rate compared to HM-1 ( $P$-value $<0.05$, Figure $2 E)$. In addition, MTZR adhered to plastic surfaces, and to fibronectinand collagen-coated plates at relatively comparable levels, but not as efficiently as HM-1 (Supplementary Figure S2).

\section{Transcriptomic Analysis of MTZR}

Our expression data showed variations in the number of differentially expressed genes between MTZR and HM-1 cultured with and without MTZ (GEO ID: GSE35990). To identify genes whose expression was most highly affected, a general filtering of the expression data, as indicated in Materials and Methods, was used. This resulted in the identification of 142 probe sets for MTZR, 58 probe sets for MTZR (-), and 37 probe sets for HM-1 (+) that showed at least 3-fold changes compared to HM1 (-) (Figure 3A, Table S3). In MTZR, 95 (66.9\%) of the genes were upregulated, while $47(33.1 \%)$ genes were downregulated (Tables 2, 3). Only 55 (38.7\%) genes were annotated after conducting BLAST search, while 87 (61.3\%) genes encoded for proteins of unknown function, i.e., hypothetical proteins (Table S4). The most upregulated gene was a hypothetical protein (HP) (EHI_006850) with some similarity to a zinc finger protein in $E$. histolytica $\left(E\right.$-value $\left.=1.0 \mathrm{e}^{-46}\right)$, designated as HP1 in this study. Its expression in MTZR was increased by 36.9 folds. Genes for DNA polymerase (EHI_164190), iron-sulfur flavoprotein (ISF) (EHI_025710), AIG1 family protein [XP_648192 (522.m00018)], and four other HPs were also upregulated by more than 10 folds. The most downregulated genes were three leucine-rich proteins [EHI_033560,EHI_077280,EHI_124070(371.m00031)] which had fold changes of more than 160, and two AIG family 

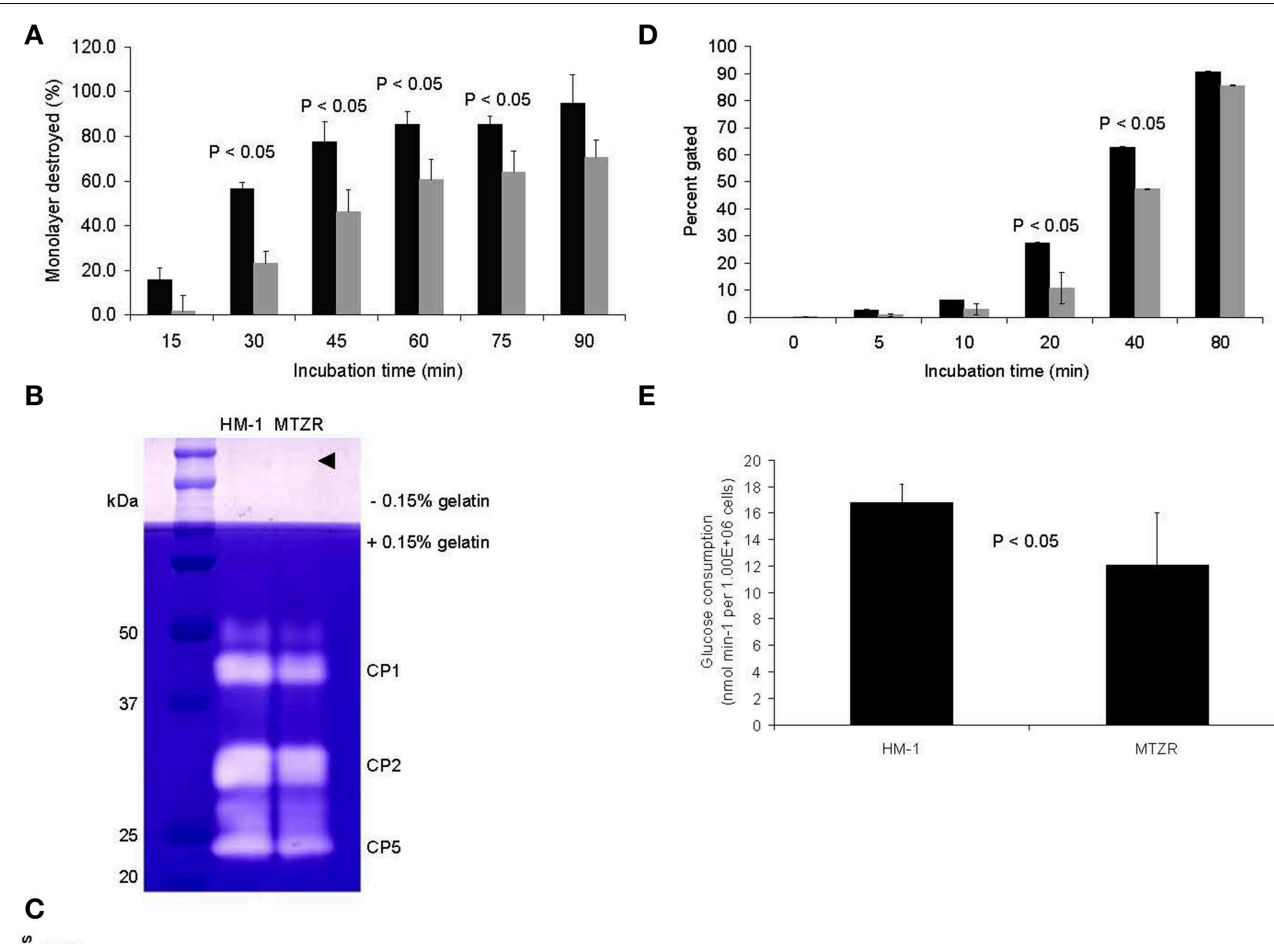

E
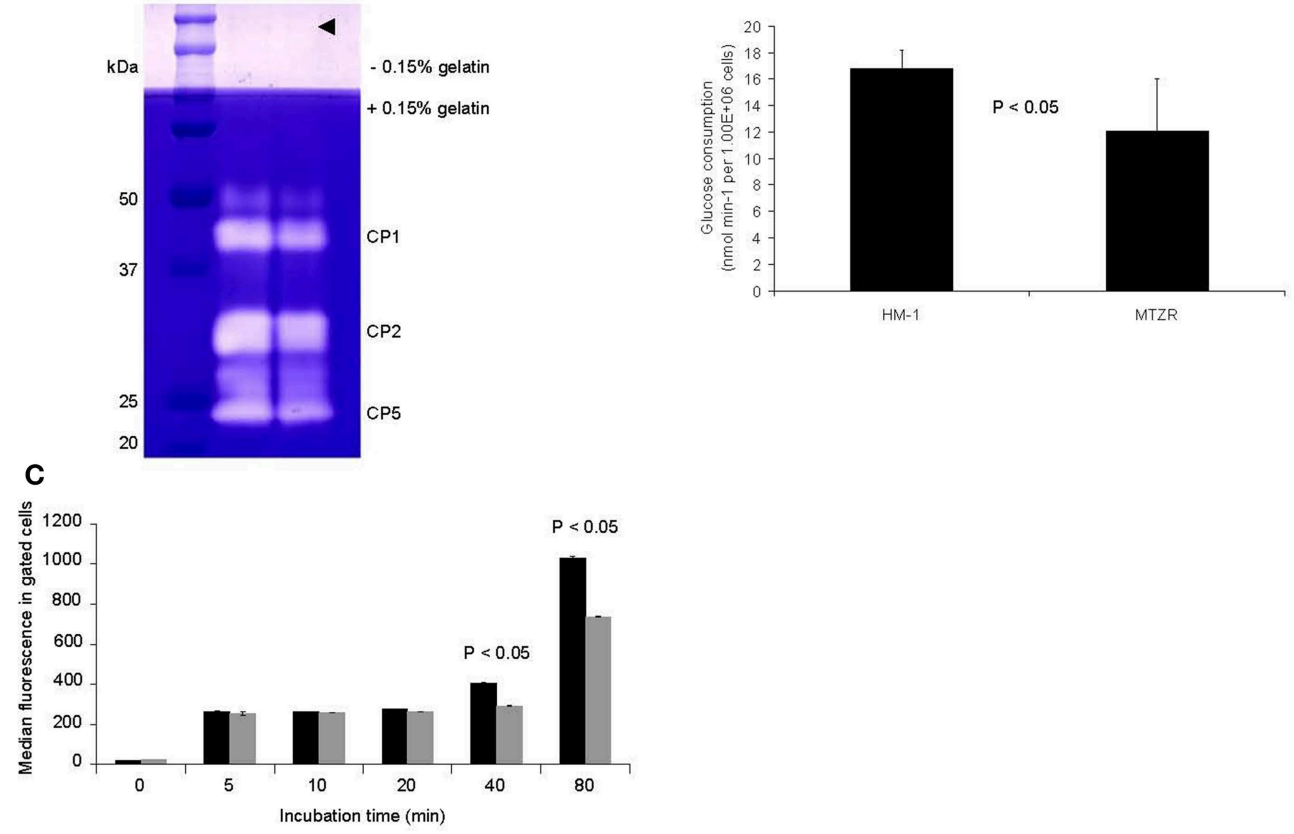

FIGURE 2 | Phenotypic changes observed in MTZR. Statistical significance is indicated $(P$-value $<0.05)$. (A) $\mathrm{CHO}$ monolayer destruction assay of HM-1 (black bars) and MTZR (gray bars). (B) Zymography of whole cell lysates of HM-1 and MTZR. An arrowhead indicates comparable protein loading per lane as estimated by CBB

proteins [XP_648014 (628.m00011), EHI_180390] and two CPs (EHI_160330, EHI_121160) genes that were downregulated by at least 5 folds. The two CPs identified had high similarity to CP7 (synonymous to EhCP-B1) (81\%) based on amino acid sequence (Tillack et al., 2007). The differential expression of 16 genes was validated by qRT-PCR, using rpoII as an endogenous control (Table 4). Pearson's correlation coefficient ( 0.81 ) between microarray and qRT-PCR results indicated a reasonable degree of concordance between the fold-changes of the genes selected for this comparison.

To determine whether the genes we identified were important in MTZ resistance or resulted from a general stress response, a 3-way comparison of differentially expressed genes in MTZR, MTZR (-) and HM-1 (+) was performed. Figures 3A,B, and Table S3 show that out of 142 genes modulated in MTZR, 48 genes (33.8\%) were also modulated in MTZR $(-)$, while only 8 genes (5.6\%) were differentially transcribed in HM-1 (+). Among the genes specifically modulated staining of irrelevant proteins. (C,D) Phagocytosis assay with carboxylated beads in HM-1 (black bars) and MTZR (gray bars). The number of beads phagocytosed (C) and the percentage of cells with engulfed beads (D) at indicated time points are compared between $\mathrm{HM}-1$ and MTZR. (E) Glucose consumption assay. in MTZR were DNA polymerase (EHI_164190), 4 AIG1 family proteins [EHI_026000, EHI_126550, EHI_126560, XP_648127 (554.m00020)], four iron-sulfur flavoproteins (EHI_022270, EHI_022600, EHI_181710, EHI_067720, EHI_103260), metal-dependent hydrolase (EHI_054690), dUTP nucleotidohydrolase domain-containing protein (EHI_072960), three serine-rich $25 \mathrm{kDa}$ antigen protein [EHI_073980, EHI_072000, EHI_072000 (82.m00164)], two Ras family protein (EHI_074750, EHI_045600), Rho guanine nucleotide exchange factor (EHI_006140), and a competence/damage-inducible protein (EHI_090260). In MTZR (-), AP-2 complex protein (EHI_014390), serine acetyltransferase (EHI_021570), zinc finger protein (EHI_091050), cysteine protease (EHI_117650), and a cell division control protein (EHI_154270) were specifically modulated. In HM-1 (+), on the other hand, genes for heat shock proteins [EHI_005657 (181.m00064), EHI_156560 (482.m00014), EHI_034710)] were specifically upregulated together with genes putatively involved in drug resistance 
A

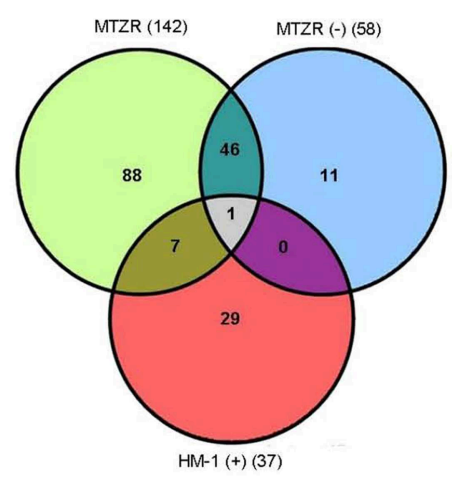

B

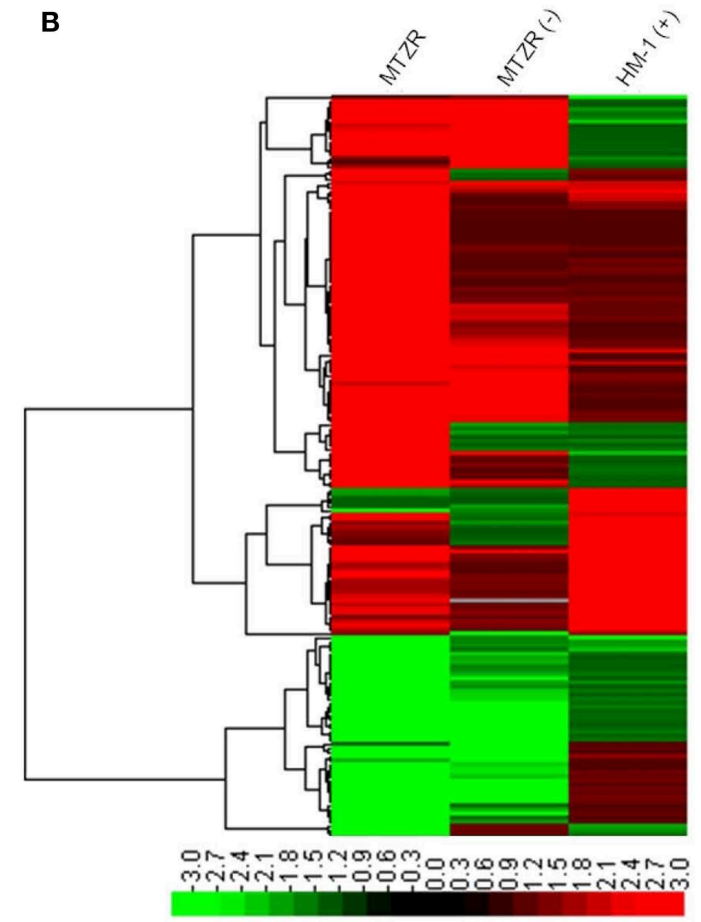

FIGURE 3 | Venn diagram (A) and heat map (B) of modulated genes in MTZR, MTZR (-), and HM-1 (+). Note that most of genes that were transcriptionally regulated in MTZR were specific to the strain when cultured with MTZ.

like P-glycoprotein 5 (EHI_075410, EHI_125030) and ATPbinding cassette protein (EHI_134470, EHI_178580). Two iron-sulfur flavoproteins (EHI_025710, EHI_138480) and an ABC transporter [EHI_084730 (36.m00218)] were upregulated in both MTZR and HM-1 (+), although their expression in HM1 $(+)$ was 2 to 3 folds higher. It is also interesting to note that in all three strains, induction of gene transcription clearly prevailed over inhibition. This was particularly true for HM-1 (+) where almost $95 \%$ of the modulated genes were upregulated.

\section{Go Classification, Features, and Clustering on the Genome}

To have a general view of the cellular functions regulated as a result of $\mathrm{MTZ}$ resistance, we performed a GO enrichment analysis. A total of $132 \mathrm{GO}$ terms were mined from Amoeba DB representing 63 unique GO IDs (Table S5). However, based on Fisher's exact test, only 24 terms were significantly enriched in MTZR (Table 5). Genes involved in GTP binding and proteolysis were the most highly enriched, followed by genes associated with cysteine-type peptidase activity, small GTPase-mediated signal transduction, oxidoreductase activity, protein kinase activity, and electron carrier activity. Roughly, the enriched terms could be classified into four functional categories, namely (1) nucleotide binding, (2) metabolism, (3) oxidative stress response, and (4) signal transduction.

Only a fraction of the differentially expressed genes in MTZR (about 5\%) encoded for membrane proteins, based on positive results for transmembrane and signal peptide predictions
(Table S6). Only 21 genes (14.8\%) contained at least one transmembrane domain. Eleven of these were upregulated, while 10 were downregulated. Proteins encoded by 25 genes (17.6\%) also had predicted signal peptides. Only seven genes have both transmembrane domains and signal peptides. Only one, however, was annotated as tyrosine kinase (EHI_118410), while the rest were all genes for HPs.

Most of the modulated genes were encoded on different scaffolds. Thirty-four genes (30.6\% of EHI-probe sets), however, formed 15 sets of dyads or triads that occupied the same contig (Table S7). Included were genes for four AIG1 family proteins (EHI_126550, EHI_126560, EHI_176700, EHI_176580) and two Ras family proteins (EHI_045450, EHI_045600). In four sets of genes, the members were found to be located on opposite strands, but the regulation of their expression was the same and their foldchanges were comparable. For some genes found on the same strand, the distance between the genes was less than $1 \mathrm{~kb}$. It was therefore possible for these genes to be co-regulated by the same transcription factor.

\section{Functional Analysis}

To study further the relationship between the expression of some of the modulated genes in MTZR with drug resistance, generation of stable transformants overexpressing HA-tagged HP1, ISF1, ISF2, and ISF4 was performed (Figure 4A). The mRNA level of these proteins was estimated by qRT-PCR. The levels of mRNA of HP1 and ISFs were about 5.5 or 2.5 to 3 fold, respectively, higher in MTZR compared to their expression in HM-1 transfected 
TABLE 2 | List of annotated genes that were upregulated in MTZR by $>3$ fold compared to HM-1.

\begin{tabular}{|c|c|c|c|c|}
\hline Probe Set ID & NCBI RefSeq & Gene name & $P$-value & Fold-change \\
\hline EHI_164190_at & XM_001913665.1 & DNA polymerase, putative & 2.80E-03 & 12.9 \\
\hline EHI_025710_at & XM_644279.1 & Iron-sulfur flavoprotein, putative & 4.50E-05 & 11.6 \\
\hline 522.m00018_at & XM_643100.1 & AIG1 family protein & $6.50 \mathrm{E}-04$ & 11.5 \\
\hline EHI_189960_at & XM_647238.1 & ADP-ribosylation factor 1 , putative & $9.20 \mathrm{E}-04$ & 7.2 \\
\hline EHI_026000_s_at & XM_643099.1 & AIG1 family protein, putative & 2.60E-03 & 6.5 \\
\hline EHI_138480_at & XM_650038.1 & Iron-sulfur flavoprotein, putative & $6.50 \mathrm{E}-04$ & 6.3 \\
\hline EHI_073980_s_at & XM_648468.1 & Serine-rich $25 \mathrm{kDa}$ antigen protein & 1.10E-02 & 6.2 \\
\hline EHI_022270_s_at & XM_644761.1 & Iron-sulfur flavoprotein & 1.60E-02 & 5.5 \\
\hline EHI_129890_at & XM_646723.1 & Type A flavoprotein, putative & 1.00E-02 & 5.4 \\
\hline EHI_022600_s_at & XM_643169.1 & Iron-sulfur flavoprotein & 1.40E-02 & 5.4 \\
\hline EHI_181710_s_at & XM_001914510.1 & Iron-sulfur flavoprotein, putative & 1.30E-02 & 5.3 \\
\hline 82.m00157_s_at & XM_648374.1 & Surface antigen ariel1 & $6.80 \mathrm{E}-03$ & 5.3 \\
\hline EHI_096770_at & XM_650580.1 & Acetyltransferase, putative & 1.30E-02 & 4.9 \\
\hline EHI_072960_s_at & XM_001914217.1 & dUTP nucleotidohydrolase domain protein & 3.20E-02 & 4.9 \\
\hline EHI_067720_s_at & XM_643101.1 & Iron-sulfur flavoprotein, putative & 5.30E-04 & 4.8 \\
\hline EHI_072000_s_at & XM_001913846.1 & Serine-rich $25 \mathrm{kDa}$ antigen protein, putative & $9.40 \mathrm{E}-03$ & 4.8 \\
\hline EHI_103260_s_at & XM_001913434.1 & Iron-sulfur flavoprotein & $2.30 \mathrm{E}-02$ & 4.5 \\
\hline 82.m00164_s_at & XM_648353.1 & Serine-rich $25 \mathrm{kDa}$ antigen protein & 4.10E-02 & 4.1 \\
\hline EHI_074750_at & XM_644490.1 & Ras family GTPase & 3.80E-04 & 3.9 \\
\hline EHI_148550_at & XM_652392.1 & Protein tyrosine kinase domain-containing protein & 4.10E-02 & 3.8 \\
\hline 432.m00028_at & XM_643464.1 & AIG1 family protein & $2.70 \mathrm{E}-04$ & 3.7 \\
\hline EHI_075660_at & XM_643678.1 & CAAX prenyl protease, putative & 1.70E-04 & 3.6 \\
\hline EHI_075150_at & XM_643772.2 & NAD-specific glutamate dehydrogenase, putative & $6.10 \mathrm{E}-03$ & 3.6 \\
\hline EHI_126550_at & XM_643463.2 & AIG1 family protein, putative & $2.00 \mathrm{E}-03$ & 3.5 \\
\hline EHI_082060_at & XM_646822.1 & Leucine rich repeat protein, BspA family & 1.00E-02 & 3.4 \\
\hline 36.m00218_s_at & XM_649994.1 & Truncated ABC transporter, putative & 4.80E-02 & 3.3 \\
\hline EHI_147020_at & XM_644619.1 & Ser/thr protein phosphatase family protein & 9.30E-04 & 3.3 \\
\hline EHI_092100_at & XM_649470.1 & Chitinase, putative & 4.10E-02 & 3.2 \\
\hline EHI_045450_at & XM_652204.1 & Ras family GTPase & 8.70E-04 & 3.1 \\
\hline EHI_029620_s_at & XM_642949.1 & Aldose reductase, putative & $1.20 \mathrm{E}-03$ & 3.1 \\
\hline EHI_118410_at & XM_644811.1 & Tyrosine kinase, putative & $7.20 \mathrm{E}-03$ & 3.1 \\
\hline EHI_075640_at & XM_001914030.1 & Protein phosphatase domain-containing protein & 2.10E-02 & 3.1 \\
\hline EHI_045600_at & XM_648507.1 & Ras family protein & $2.30 \mathrm{E}-02$ & 3.1 \\
\hline EHI_126560_at & XM_001914189.1 & AlG1 family protein, putative & 1.40E-02 & 3.1 \\
\hline EHI_091450_at & XM_645308.2 & Cysteine protease, putative & 9.00E-04 & 3.0 \\
\hline
\end{tabular}

with mock vector (pEhEx-HA). Transformants cultured with $10 \mu \mathrm{M}$ G418 were challenged with MTZ for $48 \mathrm{~h}$ (Figure 4B). The highest concentration shown was based on the $\mathrm{IC}_{50}$ of MTZ against HM-1, performed under the same conditions $(6.5 \mu \mathrm{M})$. No significant difference in percent survival was observed at all concentrations tested between the overexpressors and control (Figure 4B). Neither was significant difference in survival against hydrogen peroxide, observed, among the transformants (Figure 4C).

\section{Discussion}

\section{Differences in MTZR Generation in This Study and Previous Works}

Currently, only 4 studies have been published regarding E. histolytica and its response to or resistance to MTZ (Samarawickrema et al., 1997; Wassmann et al., 1999; Leitsch et al., 2007; Tazreiter et al., 2008). These studies either exposed wild-type cells to serum level concentrations of the drug $(70-100 \mu \mathrm{M})$ or generated drug resistant trophozoites, similar to what we did in this study. However, the MTZ concentrations used in these studies and ours differ, which might explain some of the differences observed. The concentration used here is slightly higher compared to those used by Samarawickrema et al. $10 \mu \mathrm{M}$ (Samarawickrema et al., 1997), but significantly lower than those used by Wassmann et al. $40 \mu \mathrm{M}$ (Wassmann et al., 1999), Tazreiter et al. $50 \mu \mathrm{M}$ (Tazreiter et al., 2008), and Leitsch et al. $50 \mu \mathrm{M}$ (Leitsch et al., 2007). Our strain adapted more quickly to $1 \mu \mathrm{M}$ MTZ compared to the strain used by Samarawickrema (7 vs. 38 days) but overall the length of time used to generate MTZR was comparable.

For reasons we do not understand, our attempts to further increase the level of resistance failed, and no resistance above the concentration used here could be established. We could 
TABLE 3 | List of annotated genes that were downregulated in MTZR by $>3$ fold.

\begin{tabular}{|c|c|c|c|c|}
\hline Probe Set ID & NCBI RefSeq & Gene name & $P$-value & Fold-change \\
\hline EHI_033560_s_at & XM_001913757.1 & Leucine rich repeat protein 1 & 2.20E-04 & 171.4 \\
\hline EHI_077280_s_at & XM_649853.2 & Leucine rich repeat protein, BspA family & 1.70E-04 & 163.1 \\
\hline 371.m00031_s_at & XM_643815.1 & BspA-like leucine rich repeat protein, putative & 3.50E-04 & 163 \\
\hline 628.m00011_at & XM_642922.1 & AIG1 family protein & 4.10E-04 & 8.4 \\
\hline EHI_160330_s_at & XM_001914054.1 & Cysteine protease, putative & 3.90E-03 & 7.3 \\
\hline EHI_121160_s_at & XM_001914417.1 & Cysteine protease, putative & 2.20E-03 & 7.3 \\
\hline EHI_054690_at & XM_646973.2 & Metal dependent hydrolase, putative & 4.90E-04 & 5.8 \\
\hline EHI_180390_at & XM_648725.1 & AIG1 family protein, putative & 2.40E-03 & 5.0 \\
\hline EHI_174230_s_at & XM_647412.2 & S-adenosylmethionine synthetase & 5.40E-03 & 4.1 \\
\hline EHI_176700_at & XM_001914268.1 & AIG1 family protein, putative & 1.00E-02 & 4.1 \\
\hline EHI_179060_at & XM_651187.2 & Glycosyltransferase & 9.10E-03 & 3.6 \\
\hline EHI_176580_at & XM_643164.1 & AlG1 family protein, putative & 5.90E-04 & 3.5 \\
\hline EHI_090260_at & XM_645039.1 & Competence/damage-inducible protein, putative & 6.80E-04 & 3.4 \\
\hline EHI_020250_at & XM_643256.1 & Lecithin:cholesterol acyltransferase protein & 7.30E-03 & 3.3 \\
\hline 2.m00624_s_at & XM_652243.1 & Protein kinase, putative & 3.20E-02 & 3.3 \\
\hline EHI_006140_at & XM_648345.1 & Rho guanine nucleotide exchange factor, putative & 3.00E-02 & 3.2 \\
\hline EHI_026360_s_at & XM_650291.1 & Phosphoserine aminotransferase, putative & 6.30E-03 & 3.2 \\
\hline 554.m00020_s_at & XM_643035.1 & AIG1 family protein, putative & 3.00E-03 & 3.0 \\
\hline EHI_067220_at & XM_647568.1 & Rho family GTPase & 1.90E-03 & 3.0 \\
\hline EHI_061760_at & XM_643432.1 & Protein folding regulator & 2.00E-02 & 3.0 \\
\hline
\end{tabular}

TABLE 4 | qRT-PCR validation of selected genes from our microarray data.

\begin{tabular}{|c|c|c|c|c|}
\hline Probe set ID & Gene name & Fold change by Microarray & Fold change by qRT-PCR & Regulation \\
\hline EHI_096770_at & Acetyltransferase, putative & 4.9 & 4.6 & Upregulated \\
\hline EHI_176700_at & AlG1 family protein, putative & 4.1 & 5.1 & Downregulated \\
\hline EHI_126550_at & AlG1 family protein, putative & 3.5 & 5.1 & Upregulated \\
\hline EHI_164190_at & DNA polymerase, putative & 12.9 & 2.5 & Upregulated \\
\hline EHI_006850_at & Hypothetical protein 1 & 36.9 & 57.8 & Upregulated \\
\hline EHI_165190_at & Hypothetical protein 2 & 27.1 & 16.3 & Upregulated \\
\hline EHI_127670_at & Hypothetical protein 3 & 17 & 25.2 & Downregulated \\
\hline EHI_087210_at & Hypothetical protein 4 & 8.9 & 22.5 & Upregulated \\
\hline EHI_054690_at & Metal dependent hydrolase, putative & 5.8 & 15.4 & Downregulated \\
\hline EHI_138480_at & Iron-sulfur flavoprotein, putative (ISF1) & 6.3 & 5.8 & Upregulated \\
\hline EHI_025710_at & Iron-sulfur flavoprotein, putative (ISF2) & 11.6 & 15.8 & Upregulated \\
\hline EHI_129890_at & Type A flavoprotein, putative & 5.4 & 3.8 & Upregulated \\
\hline EHI_022600_s_at & Iron-sulfur flavoprotein (ISF4) & 5.4 & 8.1 & Upregulated \\
\hline EHI_075150_at & NAD-specific glutamate dehydrogenase, putative & 3.6 & 16.8 & Upregulated \\
\hline EHI_147020_at & Ser/thr protein phosphatase family protein & 3.3 & 1.9 & Upregulated \\
\hline EHI_118410_at & Tyrosine kinase, putative & 3.1 & 2.3 & Upregulated \\
\hline
\end{tabular}

not culture MTZR consistently at drug concentrations higher than $12 \mu \mathrm{M}$. In contrast, strains of Trichomonas and Giardia can be readily adapted to grow at $584 \mu \mathrm{M}$ and $115 \mu \mathrm{M} \mathrm{MTZ \text {, }}$ respectively (Kulda et al., 1984; Townson et al., 1992). Our results are therefore consistent with previous reports indicating that MTZ resistant strains are more difficult to generate in E. histolytica (Samarawickrema et al., 1997). While the concentration we used is several times lower than serum levels after MTZ treatment (Van Oosten et al., 1986), the changes we observed may still provide insights as to what occurs in the parasite in vivo. It was previously reported that in an abscess, parasites encounter significantly lower levels of drug than those found in the serum as drug penetration is limited by poor perfusion and mechanical barriers such as fibrin clots and the abscess wall (Sirinek, 2000).

\section{Decrease in Growth and Reversibility of Resistance in MTZR}

Formation of drug resistance is often accompanied by fitness costs (Andersson and Hughes, 2010). One particular cost, 
TABLE 5 | List of GO terms that were significantly enriched in MTZR.

\begin{tabular}{|c|c|c|c|c|}
\hline GO ID & GO Name & Aspect & Count & $p$-value \\
\hline GO:0005525 & GTP binding & Function & 14 & 3.95E-06 \\
\hline GO:0005622 & Intracellular & Component & 11 & 8.89E-03 \\
\hline GO:0006508 & Proteolysis & Process & 10 & 2.78E-08 \\
\hline GO:0007264 & Small GTPase mediated signal transduction & Process & 8 & 4.58E-05 \\
\hline GO:0008234 & Cysteine-type peptidase activity & Function & 8 & 5.09E-09 \\
\hline GO:0004713 & Protein tyrosine kinase activity & Function & 5 & $5.20 \mathrm{E}-10$ \\
\hline GO:0006508 & Proteolysis & Process & 4 & 1.34E-02 \\
\hline GO:0009055 & Electron carrier activity & Function & 4 & 9.26E-05 \\
\hline GO:0015031 & Protein transport & Process & 3 & 3.99E-03 \\
\hline GO:0003887 & DNA-directed DNA polymerase activity & Function & 2 & 2.06E-02 \\
\hline GO:0006260 & DNA replication & Process & 2 & 2.66E-02 \\
\hline GO:0006520 & Cellular amino acid metabolic process & Process & 2 & 1.84E-03 \\
\hline GO:0008408 & $3^{\prime}-5^{\prime}$ exonuclease activity & Function & 2 & 7.91E-04 \\
\hline GO:0010181 & FMN binding & Function & 2 & 3.29E-03 \\
\hline GO:0035023 & Regulation of Rho protein signal transduction & Process & 2 & 4.95E-02 \\
\hline GO:0004648 & O-Phospho-L-serine:2-oxoglutarate aminotransferase activity & Function & 1 & 5.39E-03 \\
\hline GO:0006564 & L-Serine biosynthetic process & Process & 1 & 5.39E-03 \\
\hline GO:0006913 & Nucleocytoplasmic transport & Process & 1 & 5.39E-03 \\
\hline GO:0008483 & Transaminase activity & Function & 1 & 3.71E-02 \\
\hline GO:0050662 & Coenzyme binding & Function & 1 & 4.23E-02 \\
\hline
\end{tabular}

reduction in growth rate, is the main parameter that determines the rate by which resistance develops and level of resistance reached. Similar to resistant strains previously generated (Samarawickrema et al., 1997; Wassmann et al., 1999), the doubling time of MTZR was longer compared to HM-1. Fitness cost in growth associated with drug resistance are well documented in mammalian cells, e.g., lymphoma and cancer cells (Lee, 1993; Bishop et al., 2001). It should be noted, however, that the growth kinetics of MTZR in the absence of drug pressure improved over time. This indicates that some of the drugselection-induced changes developed by MTZR were temporal and reversible. This also indicates that cells in the culture may have varying degrees of resistance. In addition, MTZR (-) that was re-exposed to MTZ showed significantly lower growth compared to MTZR, but slightly higher compared to HM-1, which may indicate that some drug-selection-induced changes in MTZR were still operative even after the removal of drug pressure.

\section{Cross-Resistance in MTZR}

The resistance level displayed by MTZR is significantly lower compared to previous reports: the $\mathrm{IC}_{50}$ value of $12 \mu \mathrm{M}$ in this study compared to $40 \mu \mathrm{M}$ in the previous study (Samuelson, 1999; Wassmann et al., 1999). However, its survival in otherwise lethal concentration of MTZ for long periods of incubation, does indicate reduced sensitivity and resistance. The cross-resistance of MTZR to ornidazole and tinidazole is not surprising, because both are 5-nitroimidazoles like MTZ. It is therefore likely that their mode of action and mechanism of resistance were similar (Pasupuleti et al., 2014). T. vaginalis isolates that were characterized as having very high resistance to MTZ were similarly insensitive to tinidazole (Narcisi and Secor, 1996). In the case of paromomycin, emetine, chloroquine, and hydrogen peroxide, it is possible that the reduced sensitivity was nonspecific and could be due to an increased capacity of MTZR to deal with stress. Studies have shown that cell lines resistant to one drug are often cross-resistant to closely related drugs or to unrelated compounds when their mode of action is the same or when they carry membrane alterations (Upcroft and Upcroft, 1993).

\section{Decreased Adhesion, Phagocytosis, Cytolysis, and Virulence in MTZR}

In E. histolytica, establishment and outcome of infection depend heavily on adhesive and invasive capacity (Flores-Romo et al., 1997). Recently, drug resistance has been shown to modulate these factors and vice versa (Giha et al., 2006). The decreased rate of adhesion observed in MTZR indicated that MTZ selection negatively affected the synthesis or expression of surface adhesion molecules. While other studies have shown that cell adhesion is a key determinant in drug resistance (Shain and Dalton, 2001), this apparently was not the case in MTZ resistance. Inhibition of adherence in this parasite has previously been 


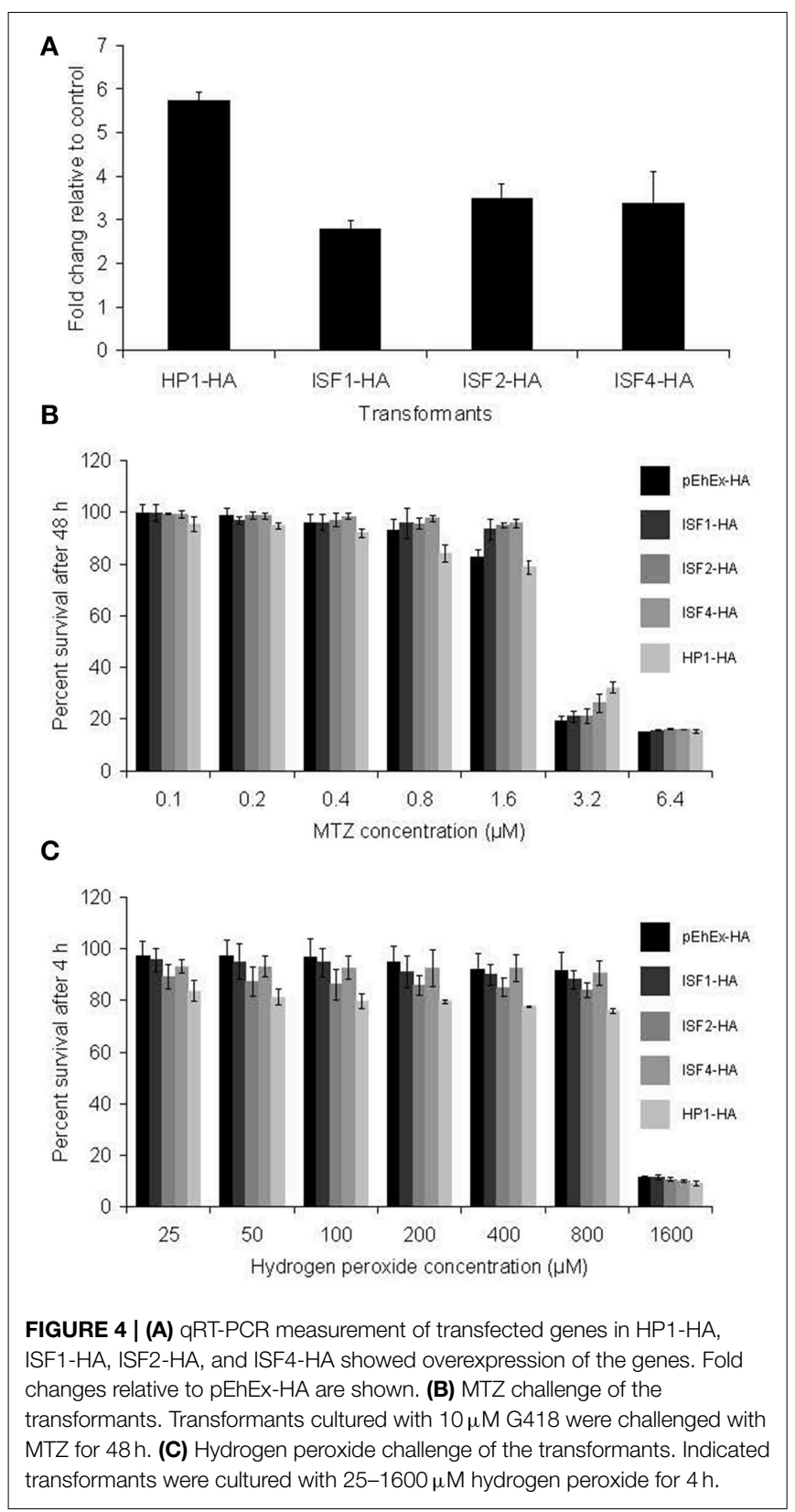

shown to decrease host cell cytotoxicity (Ravdin et al., 1985) and experimental evidence strongly suggests the involvement of surface adhesins in phagocytosis (Heron et al., 2011). As shown in the results, MTZR also had decreased cytopathy and phagocytosis (Figures 2A,C). The decreased band intensity for CP1 and CP2 in the zymogram may partially explain this phenotype. CP1 has been shown to be upregulated in a mouse model of amebic colitis following invasion (Gilchrist et al., 2006), while CP2 has been reported to contribute to intestinal damage and liver abscess formation (Hellberg et al., 2001). Our microarray data, however, did not show any significant repression of these genes, except for two uncharacterized CPs that were repressed by more than 7 folds. These CPs had high similarity (81\%) to CP7 (also called EhCP-B1) based on amino acid sequence (Tillack et al.,
2007). No significant change was observed in the expression of the genes known to be involved in the inactivation and intracellular trafficking of CPs such as intrinsic inhibitors of CPs (Sato et al., 2006) and cysteine protease binding protein family 1 (Nakada-Tsukui et al., 2012) and other lysosomal hydrolase carriers (Furukawa et al., 2012, 2013; Marumo et al., 2014). It is also possible, however, that resistance to MTZ may not necessarily result to decreased virulence in vivo.

\section{Implications from Transcriptomic Profiling of MTZR}

Our transcriptomic profiling suggests that the transcriptomic changes we observed in MTZR strain cultured with MTZ were a combination of the changes responsible for MTZ resistance and those associated with the adaptation to stresses caused by the exposure to MTZ. However, we believe that among the observed changes, the changes that were specific to MTZR strain with MTZ and absent in HM-1 with MTZ were responsible, at least in part, for resistance, rather than adaptation. This is based on the following observations: the transcriptomic profile of $E$. histolytica HM-1 cultured with MTZ was remarkably different from that of MTZR strain cultured with MTZ, while MTZR strain cultured with or without MTZ showed similar transcriptomic profiles. In other words, a larger number of common changes in gene expression were identified between MTZR strain cultured with MTZ and those without MTZ when compared between MTZR strain cultured with MTZ and HM-1 cultured with MTZ.

GO enrichment of MTZR-associated transcriptomic changes revealed regulation of genes encoding for proteins potentially involved in nucleotide binding, metabolism, oxidative stress response, and signal transduction. These are apparently the processes most influenced by MTZ resistance. However, since most of the genes are without GO annotations, it is likely that additional processes are involved. When we examined the genomic locations of these genes, we found that $30 \%$ of them formed dyads or triads that occupied the same contig. While some genes forming dyads and triads are apart by more than $10 \mathrm{~kb}$, the distance between some of the adjacent genes in dyads and triads was less than $1 \mathrm{~kb}$. Thus, co-expression of some genes in dyads and triads in MTZR could be attributed to a shared regulatory system.

Consistent with previous findings, no significant difference in PFOR mRNA levels was observed between MTZR and HM-1 (Samarawickrema et al., 1997; Wassmann et al., 1999; Tazreiter et al., 2008). This observation could mean 3 things. First, it's likely that the level of resistance achieved in this study was not sufficient to downregulate PFOR, although a similar finding was reported in strains resistant to $40 \mu \mathrm{M}$ MTZ (Wassmann et al., 1999). Second, since E. histolytica lacks pyruvate dehydrogenase (Clark et al., 2007; Tazreiter et al., 2008) or pyruvate decarboxylase (Lo and Reeves, 1978), the significance of PFOR cannot be overstated. The lack of an alternative enzyme to compensate for its downregulation makes this enzyme difficult to repress without severe consequences to the ameba. Third, in contrast to Giardia and Trichomonas, lack of PFOR downregulation may indicate the existence of an alternative mechanism for MTZ resistance in this parasite. It should be noted, however, that clinically resistant 
isolates of Trichomonas have been reported with no decrease in PFOR activity (Müller and Gorrell, 1983).

Two previous studies have reported the upregulation of Fe-SOD and downregulation of Fdx in the MTZ resistant ameba (Samarawickrema et al., 1997; Wassmann et al., 1999). In the previous work, fold changes were determined based on enzyme activity assay or northern blot (Samarawickrema et al., 1997; Wassmann et al., 1999). Disparity, however, between changes in mRNA abundance and enzyme activity have been reported, and in some cases, increases in enzyme activity can exceed those of mRNA abundance (Glanemann et al., 2003). Interestingly, the lack of Fe-SOD modulation in cells exposed to MTZ was also reported by Tazreiter et al. (2008). On the contrary, in this work, neither gene was modulated significantly. It is possible that similar to PFOR, differences in resistance levels could explain the lack of modulation in the levels of Fe-SOD and Fdx. Other studies also indicated that Fe-SOD and Fdx are not tightly associated with MTZ resistance. It was shown that parasites in which Fdx was repressed did not display full resistance to MTZ (Rasoloson et al., 2002) and in bacteria, increased SOD activity was not always associated with MTZ resistance (Smith and Edwards, 1995).

In this study, genes involved in nucleic acid synthesis and binding, stress response, metabolism, and vesicular trafficking were mostly affected in MTZR. The significance of these genes relative to phenotypic changes and drug resistance will be discussed here through their known roles in E. histolytica or in other organisms, in regulating key cell functions. One should also note that since only a single MTZ resistant line was analyzed in this study, it is possible that MTZ resistance can be also conferred by the mechanisms that are independent of those described in this study.

\section{Nucleic Acid Synthesis and Binding}

In prokaryotes, upregulation of DNA polymerases imparts plasticity to their genome, allowing them to adapt in unfavorable environmental conditions (Joseph et al., 2006). It has been suggested that pathogenic bacteria utilize this adaptation to develop resistance against therapeutic agents (Karpinets et al., 2006). Since it has been shown that primary effect of MTZ is rapid inhibition of DNA replication (Ludlum et al., 1988; Sisson et al., 2000; Leitsch et al., 2007), the upregulation of a DNA polymerase (EHI_164190) in this study may indicate that this mode of action is operative in MTZ resistance. One hypothetical protein identified in this study (HP1, EHI_006850) has some similarity to zinc finger proteins, which are known to be involved in DNA recognition, RNA packaging, and transcriptional activation (Laity et al., 2001). It has an NAD+ binding pocket and a tetrachlorodibenzo-p-dioxin (TCDD)inducible poly(ADP-ribose) polymerase (PARP)-like domain that is involved in the attachment of ADP-ribose units to DNA-binding proteins (Ma et al., 2001). It's also known to be a regulatory component induced by DNA damage and an enzyme involved in DNA repair (Nguewa et al., 2006; MarchlerBauer et al., 2011). The dUTP nucleotidohydrolase (EHI_072960) upregulated in MTZR may be involved in the removal of dUTP from the dNTP pool, de novo biosynthesis of dTTP, and DNA replication as reported (Richards et al., 1984; Gadsden et al., 1993). In cancer cells, high level of dUTPase is implicated as a mechanism of resistance to chemotherapy (Ladner et al., 2000).

\section{Stress Response}

ISFs that were modulated in MTZR are part of family of redoxactive proteins mainly found in anaerobic prokaryotes (Andrade et al., 2005). In NCBI, 18 ISF genes are annotated in the $E$. histolytica genome, although $50 \%$ of these are identical proteins (http://www.ncbi.nlm.nih.gov/). In this study 7 ISF probe sets were upregulated by at least 4 folds in MTZR. The overexpression of ISF1 (EHI_138480) was also observed in HM-1 (+), while ISF2 was upregulated in both MTZR (-) and HM-1 (+). These 2 ISFs were upregulated in HM-1 (+) by least 20 folds, compared to 6 to 11 folds in MTZR, hinting that these genes are involved in stress response. These two genes were also induced in $E$. histolytica cultured under L-cysteine deprived and oxidative stress conditions (Vicente et al., 2009; Husain et al., 2011), but were downregulated in a mouse model of intestinal amebiasis (Gilchrist et al., 2006). Our findings together with these reports suggest that induction of these ISFs, particularly ISF1, is an adaptation that may enhance survival when cells experience environmental stress.

\section{Metabolism}

Several metabolic genes were upregulated in MTZR. NADspecific glutamate dehydrogenase (EHI_075150) catalyzes the oxidative deamination of glutamate to $\alpha$-ketoglutarate using NAD as cofactor (Plaitakis and Zaganas, 2001; Girinathan et al., 2014). Most likely, its upregulation is a part of stress response. In humans, its activity is regulated through ADP-ribosylation, and interestingly, Arf1 (EHI_189960) was also upregulated in this study (Herrero-Yraola et al., 2001). Chitinase (EHI_092100) (Escueta- De Cadiz et al., 2013) was also upregulated in MTZR and MTZR (-) by at least 3 folds, although its precise role in drug resistance is not known. In plants, its upregulation plays a defensive role against toxins and antibiotics (Gooday, 1999). Aldose reductase (EHI_029620), on the other hand, can reduce a broad spectrum of substrates including cytotoxic aldehydes (Ramana, 2011). Its upregulation in human liver cancer cells was associated with resistance to daunorubicin and was confirmed by sensitizing cells to the drug by the addition of aldose reductase inhibitors (Lee et al., 2001).

The decrease in cell growth observed in MTZR may be partially explained by the repression of phosphoserine aminotransferase (EHI_026360) (Ali and Nozaki, 2006; Mishra et al., 2010), which catalyzes the conversion of 3-phosphohydroxypyruvate to L-phosphoserine, the second step of phosphorylated serine biosynthetic pathway (Ali and Nozaki, 2006). L-serine has a well-recognized role in cell proliferation, providing precursors for amino acids, protein synthesis, and nucleotide synthesis (Nozaki et al., 2005; Tabatabaie et al., 2010). The downregulation of this enzyme, therefore, may contribute to the decreased growth rate. The repression of lecithin: cholesterol acyltransferase (EHI_020250) may also be associated with decreased growth rate, because the 
enzyme is crucial in the maturation, remodeling, and metabolism of high density lipoprotein, HDL (Calabresi et al., 2011).

\section{BspA1 Gene Family}

Several genes encoding for leucine-rich repeat (LRR) proteins of the BspA family were also modulated in MTZR, and were the most downregulated genes with fold changes of more than 150. LRR is known to provide a structural framework for the formation of protein-protein interactions and serve as recognition motifs for surface proteins (Kobe and Kajava, 2001). BspA family protein was originally identified in Bacteroides forsythus and the LRR motifs of the BspA protein have been linked to cell binding to components of the extracellular matrix (Sharma et al., 1998). It is therefore possible that their downregulation may partially explain the reduced adhesion seen in MTZR. It was previously shown that an LRR BspA family protein in E. histolytica was located primarily on the plasma membrane, although it did not show whether the protein was involved in surface interactions (Davis et al., 2006).

\section{AIG1 Gene Family}

The E. histolytica AIG1 gene family consists of 47 members (Biller et al., 2010), and in this study 10 genes were found to be differentially expressed by 3 to 11 folds. Members of this protein family contain a domain found in Arabidopsis protein AIG1, which is likely involved in plant recognition and resistance to bacterial pathogens (Reuber and Ausubel, 1996). In E. histolytica, however, some AIG proteins appear to be linked with virulence. Comparative genomic analysis of Japanese clinical isolates indicated that an AIG family protein (EHI_176590) and the region around it were uniquely present in KU50, a strain isolated from a diarrheic patient, but absent in a non-pathogenic isolate called KU27 (Nakada-Tsukui et al., unpublished data). Interestingly, the same gene was downregulated by 2.7 folds in MTZR, and two adjacent genes encoding for AIG family proteins (EHI_176580 and EHI_176700) were also repressed by 3 to 4 folds. A previous study also reported the upregulation of an AIG family protein (EHI_180390) in a pathogenic strain of E. histolytica (Biller et al., 2010), although here the same gene was downregulated by 5 folds. It is therefore possible that the downregulation of these AIG family proteins might be related to the decrease in MTZR's cytopathogenicity.

Overall, we believe that these transcriptional changes participate in a global regulatory response resulting to the fitness costs and adaptive responses we observed in MTZR. The fact that more genes were upregulated than downregulated also suggests that increasing the amount of cellular components that play roles in stress response, DNA repair and others, is more important in developing low levels of resistance to MTZ than repression of proteins involved in activating the drug. Indeed, the most profound difference we observed between MTZR and HM-1 was the upregulation of genes for several ISF proteins. It should be noted, however, that more than half of the genes reported in this study are hypothetical. It is also likely that the effects of the repressed genes, although fewer in number, are more important in explaining the growth defect.

\section{Functional Analysis of Potential Resistance Genes}

In this study, we examined possible role of genes encoding HP1 and several ISF proteins in MTZ resistance. However, their episomal transfection and overexpression did not confer MTZ resistance to the extent observed in MTZR. Thus, at present, direct causal connection between HP1 and ISF overexpression and MTZ resistance has not been demonstrated. It is likely that in E. histolytica, resistance to the drug is multi-factorial in nature and requires the global regulation of genes involved in several key cell processes and not just DNA repair and stress response.

In conclusion, here we described the biological state of E. histolytica that was selected for MTZ resistance in vitro. Phenotypic and transcriptional profiling revealed fitness costs and adaptive responses that we could associate with drug resistance. Some of the consequences of resistance included decreased cell growth and virulence, which have significant implications on host-pathogen interaction and infection outcome. Comparative transcriptional analysis, on the other hand, revealed genes not previously associated with MTZ resistance in this parasite. The list of differentially transcribed genes also did not indicate in MTZR a reduced capacity to activate MTZ, but hinted on adaptations to tolerate the lethal effects of MTZ. Identifying the signaling mediators for the proteins that these genes encode, however, requires further investigation. Finally, while our data showed that high levels of MTZ resistance cannot be readily induced in vitro, the data presented here may still help researchers in better understanding the mechanisms involved should clinical cases of high levels of resistance are reported in the future.

\section{Acknowledgments}

We thank Takashi Makiuchi, Ghulam Jeelani, Yumiko SaitoNakano, and Joseph Marzo for valuable discussions. We thank Dr. Kentaro Hanada, Department of Biochemistry and Cell Biology, National Institute of Infectious Diseases for providing $\mathrm{CHO}$ cells. This work was supported by a Grant-in-Aid for Scientific Research from the Ministry of Education, Culture, Sports, Science and Technology (MEXT) of Japan (23117001, $23117005,23390099,14506236$ ), a grant for research on emerging and re-emerging infectious diseases from the Ministry of Health, Labour and Welfare of Japan (H23-Shinkosaiko-ippan-014, H26Shinkosaiko-ippan-009), a grant for research to promote the development of anti-AIDS pharmaceuticals from the Japan Health Sciences Foundation (KHA1101).

\section{Supplementary Material}

The Supplementary Material for this article can be found online at: http://journal.frontiersin.org/article/10.3389/fmicb. 2015.00354/abstract 


\section{References}

Agresti, A. (1992). A survey of exact inference for contingency tables. Stat. Sci. 7, 131-153. doi: $10.1214 / \mathrm{ss} / 1177011454$

Ali, V., and Nozaki, T. (2006). Biochemical and functional characterization of phosphoserine aminotransferase from Entameba histolytica, which possesses both phosphorylated and non-phosphorylated serine metabolic pathways. Mol. Biochem. Parasitol. 145, 71-83. doi: 10.1016/j.molbiopara.2005.09.008

Andersson, D. I., and Hughes, D. (2010). Antibiotic resistance and its cost: is it possible to reverse resistance? Nat. Rev. Microbiol. 8, 260-271. doi: 10.1038/nrmicro2319

Andrade, S. L., Cruz, F., Drennan, C. L., Ramakrishnan, V., Rees, D. C., Ferry, J. G., et al. (2005). Structures of the iron-sulfur flavoproteins from Methanosarcina thermophila and Archaeoglobus fulgidus. J. Bacteriol. 187, 3848-3854. doi: 10.1128/JB.187.11.3848-3854.2005

Benjamini, Y., and Hochberg, Y. (1995). Controlling the false discovery rate: a practical and powerful approach to multiple testing. J. R. Stat. Soc. Ser. B Stat. Methodol. 57, 289-300.

Biller, L., Davis, P. H., Tillack, M., Matthiesen, J., Lotter, H., Stanley, S. L. Jr., et al. (2010). Differences in the transcriptome signatures of two genetically related Entamoeba histlytica cell lines derived from the same isolate with different pathogenic properties. BMC Genomics 11:63. doi: 10.1186/1471-2164-11-63

Bishop, A. J., Kosaras, B., Carls, N., Sidman, R. L., and Schiestl, R. H. (2001). Susceptibility of proliferating cells to benzo[a]pyrene-induced homologous recombination in mice. Carcinogenesis 22, 641-649. doi: $10.1093 / \mathrm{carcin} / 22.4 .641$

Calabresi, L., Baldassarre, D., Simonelli, S., Gomaraschi, M., Amato, M., Castelnuovo, S., et al. (2011). Plasma lecithin:cholesterol acyltransferase and carotid intima-media thickness in European individuals at high cardiovascular risk. J. Lipid Res. 52, 1569-1574. doi: 10.1194/jlr.P014977

Clark, C. G., Cecilia, U., Alsmark, M., Hofer, M., Saito-Nakano, Y., Ali, V., et al. (2007). Structure and content of the Entamoeba histlytica genome. Adv. Parasitol. 65, 51-190. doi: 10.1016/S0065-308X(07)65002-7

Davis, P. H., Zhang, Z., Chen, M., Zhang, X., Chakraborty, S., Stanley, S. L., et al. (2006). Identification of a family of BspA like surface proteins of Entamoeba histlytica with novel leucine-rich repeats. Mol. Biochem. Parasitol. 145, 111-116. doi: 10.1016/j.molbiopara.2005.08.017

Diamond, L. S., Harlow, D. R., and Cunnick, C. C. (1978). A new medium for the axenic cultivation of Entamoeba histolytica and other Entamoeba. Trans. R. Soc. Trop. Med. Hyg. 72, 431-432. doi: 10.1016/0035-9203(78)90144-X

Diamond, L. S., Mattern, C. F., and Bartgis, I. L. (1972). Viruses of Entamoeba histolytica. I. Identification of transmissible virus-like agents. J. Virol. 9, 326-341.

Dooley, C. P., and O'Morain, C. A. (1988). Recurrence of hepatic amebiasis after successful treatment with metronidazole. J. Clin. Gastroenterol. 10, 339-342. doi: 10.1097/00004836-198806000-00022

Durel, P., Couture, J., Collart, P., and Girot, C. (1960). Flagyl (metronidazole). Br. J. Vener. Dis. 36, 154-162. doi: 10.1136/sti.36.3.154

Escueta- De Cadiz, A., Jeelani, G., Nakada-Tsukui, K., Caler, E., and Nozaki, T. (2013). Transcriptome analysis of encystation in Entamoeba invadens. PLoS ONE 8:e74840. doi: 10.1371/journal.pone.0074840

Flores-Romo, L., Estrada-García, T., Shibayama-Salas, M., Campos-Rodríguez, R., Bacon, K., Martínez-Palomo, A., et al. (1997). In vitro Entamoeba histlytica adhesion to human endothelium: a comparison using two strains of different virulence. Parasitol. Res. 83, 397-400. doi: 10.1007/s004360050271

Furukawa, A., Nakada-Tsukui, K., and Nozaki, T. (2012). Novel transmembrane receptor involved in phagosome transport of lysozymes and $\beta$-hexosaminidase in the enteric protozoan Entamoeba histlytica. PLoS Pathog. 8:e1002539. doi: 10.1371/journal.ppat.1002539

Furukawa, A., Nakada-Tsukui, K., and Nozaki, T. (2013). Cysteine proteasebinding protein family 6 mediates the trafficking of amylases to phagosomes in the enteric protozoan Entamoeba histlytica. Inf. Immun. 81, 1820-1829. doi: 10.1128/IAI.00915-12

Gadsden, M. H., McIntosh, E. M., Game, J. C., Wilson, P. J., and Haynes, R. H. (1993). dUTP pyrophosphatase is an essential enzyme in Saccharomyces cerevisiae. ЕМВО J. 12, 4425-4431.

Giha, H. A., Elbashir, M. I., A-Elbasit, I. E., A-Elgadir, T. M., ElGhazali, G. E., Mackinnon, M. J., et al. (2006). Drug resistance-virulence relationship in Plasmodium falciparum causing severe malaria in an area of seasonal and unstable transmission. Acta Trop. 97, 181-187. doi: 10.1016/j.actatropica.2005.10.004

Gilchrist, C. A., Houpt, E., Trapaidze, N., Fei, Z., Crasta, O., Asgharpour, A., et al. (2006). Impact of intestinal colonization and invasion on the Entamoeba histlytica transcriptome. Mol. Biochem. Parasitol. 147, 163-176. doi: 10.1016/j.molbiopara.2006.02.007

Girinathan, B. P., Braun, S. E., and Govind, R. (2014). Clostridium difficile glutamate dehydrogenase is a secreted enzyme that confers resistance to $\mathrm{H} 2 \mathrm{O} 2$. Microbiology 160, 47-55. doi: 10.1099/mic.0.071365-0

Glanemann, C., Loos, A., Gorret, N., Willis, L. B., O’Brien, X. M., Lessard, P. A., et al. (2003). Disparity between changes in mRNA abundance and enzyme activity in Corynebacterium glutamicum: implications for DNA microarray analysis. Appl. Microbiol. Biotechnol. 61, 61-68. doi: 10.1007/s00253-0021191-5

Gooday, G. W. (1999). Aggressive and defensive roles for chitinases. EXS 87, 157-169. doi: 10.1007/978-3-0348-8757-1_11

Hellberg, A., Leippe, M., and Bruchhaus, I. (2000). Two major 'higher molecular mass proteinases' of Entamoeba histlytica are identified as cysteine proteinases 1 and 2. Mol. Biochem. Parasitol. 105, 305-309. doi: 10.1016/S01666851(99)00194-2

Hellberg, A., Nickel, R., Lotter, H., Tannich, E., and Bruchhaus, I. (2001). Overexpression of cysteine proteinase 2 in Entamoeba histlytica or Entamoeba dispar increases amoeba-induced monolayer destruction in vitro but does not augment amoebic liver abscess formation in gerbils. Cell. Microbiol. 3, 13-20. doi: 10.1046/j.1462-5822.2001.00086.x

Heron, B. T., Sateriale, A., Teixeira, J. E., and Huston, C. D. (2011). Evidence for a novel Entamoeba histlytica lectin activity that recognises carbohydrates present on ovalbumin. Int. J. Parasitol. 41, 137-144. doi: 10.1016/j.ijpara.2010. 07.011

Herrero-Yraola, A., Bakhit, S. M., Franke, P., Weise, C., Schweiger, M., Jorcke, D., et al. (2001). Regulation of glutamate dehydrogenase by reversible ADP-ribosylation in mitochondria. EMBO J. 20, 2404-2412. doi: 10.1093/emboj/20.10.2404

Husain, A., Jeelani, G., Sato, D., and Nozaki, T. (2011). Global analysis of gene expression in response to L-cysteine deprivation in the anaerobic protozoan parasite Entamoeba histlytica. BMC Genomics 12:275. doi: 10.1186/1471-2164$12-275$

Joseph, N., Duppatla, V., and Rao, D. N. (2006). Prokaryotic DNA mismatch repair. Prog. Nucleic Acid Res. Mol. Biol. 81, 1-49. doi: 10.1016/S00796603(06)81001-9

Karpinets, T., Greenwood, D., Pogribny, I., and Samatova, N. (2006). Bacterial stationary-state mutagenesis and Mammalian tumorigenesis as stress-induced cellular adaptations and the role of epigenetics. Curr. Genomics 7, 481-496. doi: $10.2174 / 138920206779315764$

Kobe, B., and Kajava, A. V. (2001). The leucine-rich repeat as a protein recognition motif. Curr. Opin. Struct. Biol. 11, 725-732. doi: 10.1016/S0959440X(01)00266-4

Koutsaimanis, K. G., Timms, P. W., and Rée, G. H. (1979). Failure of metronidazole in a patient with hepatic amebic abscess. Am. J. Trop. Med. Hyg. 28, 768-769.

Kulda, J., Cerkasov, J., Demes, P., and Cerkasovová, A. (1984). Tritrichomonas foetus: stable anaerobic resistance to metronidazole in vitro. Exp. Parasitol. 57, 93-103. doi: 10.1016/0014-4894(84)90068-7

Kulda, J., Kabíçková, H., Tachezy, J., Çerkasovová, A., and Çerkasov, J. (1989). "Metronidazole resistant trichomonads: mechanisms of in vitro developed anaerobic resistance," in Biochemistry and Molecular Biology of 'Anaerobic' Protozoa, eds D. Lloyd, G. H. Coombs and T. A. P. Paget (Chur: Harwood Academic Publishers), 137-160.

Lacey, S. L., Moss, S. F., and Taylor, G. W. (1993). Metronidazole uptake by sensitive and resistant isolates of Helicobacter pylori. J. Antimicrob. Chemother. $32,393-400$.

Ladner, R. D., Lynch, F. J., Groshen, S., Xiong, Y. P., Sherrod, A., Caradonna, S. J., et al. (2000). dUTP nucleotidohydrolase isoform expression in normal and neoplastic tissues: association with survival and response to 5 -fluorouracil in colorectal cancer. Cancer Res. 60, 3493-3503.

Laity, J. H., Lee, B. M., and Wright, P. E. (2001). Zinc finger proteins: new insights into structural and functional diversity. Curr. Opin. Struct. Biol. 11, 39-46. doi: $10.1016 /$ S0959-440X(00)00167-6 
Land, K. M., and Johnson, P. J. (1999). Molecular basis of metronidazole resistance in pathogenic bacteria and protozoa. Drug Resist. Updat. 2, 289-294. doi: 10.1054/drup.1999.0104

Lee, K. W., Ko, B. C., Jiang, Z., Cao, D., and Chung, S. S. (2001). Overexpression of aldose reductase in liver cancers may contribute to drug resistance. Anticancer Drugs 12, 129-132. doi: 10.1097/00001813-200102000-00005

Lee, W. P. (1993). The role of reduced growth rate in the development of drug resistance of HOB1 lymphoma cells to vincristine. Cancer Lett. 73, 105-111. doi: 10.1016/0304-3835(93)90251-4

Leiros, H. K., Kozielski-Stuhrmann, S., Kapp, U., Terradot, L., Leonard, G. A., and McSweeney, S. M. (2004). Structural basis of 5-nitroimidazole antibiotic resistance: the crystal structure of NimA from Deinococcus radiodurans. J. Biol. Chem. 279, 55840-55849. doi: 10.1074/jbc.M408044200

Leitsch, D., Burgess, A. G., Dunn, L. A., Krauer, K. G., Tan, K., Duchêne, M., et al. (2011). Pyruvate:ferredoxin oxidoreductase and thioredoxin reductase are involved in 5-nitroimidazole activation while flavin metabolism is linked to 5-nitroimidazole resistance in Giardia lamblia. J. Antimicrob. Chemother. 66, 1756-1765. doi: 10.1093/jac/dkr192

Leitsch, D., Kolarich, D., Wilson, I. B., Altmann, F., and Duchêne, M. (2007). Nitroimidazole action in Entamoeba histlytica: a central role for thioredoxin reductase. PLoS Biol. 5:e211. doi: 10.1371/journal.pbio.0050211

Livak, K. J., and Schmittgen, T. D. (2001). Analysis of relative gene expression data using real-time quantitative PCR and the 2(-Delta Delta C(T)) Method. Methods 25, 402-408. doi: 10.1006/meth.2001.1262

Lo, H. S., and Reeves, R. E. (1978). Pyruvate-to-ethanol pathway in Entamoeba histlytica. Biochem. J. 171, 225-230.

Löfmark, S., Edlund, C., and Nord, C. E. (2010). Metronidazole is still the drug of choice for treatment of anaerobic infections. Clin. Infect. Dis. 50, S16-S23. doi: 10.1086/647939

Loftus, B., Anderson, I., Davies, R., Alsmark, U. C., Samuelson, J., Amedeo, P., et al. (2005). The genome of the protist parasite Entamoeba histolytica. Nature 433, 865-868. doi: 10.1038/nature03291

Ludlum, D. B., Colinas, R. J., Kirk, M. C., and Mehta, J. R. (1988). Reaction of reduced metronidazole with guanosine to form an unstable adduct. Carcinogenesis 9, 593-596. doi: 10.1093/carcin/9.4.593

Ma, Q., Baldwin, K. T., Renzelli, A. J., McDaniel, A., and Dong, L. (2001). TCDD-inducible poly(ADP-ribose) polymerase: a novel response to 2,3,7,8tetrachlorodibenzo-p-dioxin. Biochem. Biophys. Res. Commun. 289, 499-506. doi: 10.1006/bbrc.2001.5987

Marchler-Bauer, A., Lu, S., Anderson, J. B., Chitsaz, F., Derbyshire, M. K., DeWeese-Scott, C., et al. (2011). CDD: a Conserved Domain Database for the functional annotation of proteins. Nucleic Acids Res. 39, D225-D229. doi: 10.1093/nar/gkq1189

Marie, C., and Petri, W. A. Jr. (2014). Regulation of virulence of Entamoeba histolytica. Annu. Rev. Microbiol. 68, 493-520. doi: 10.1146/annurev-micro091313-103550

Marumo, K., Nakada-Tsukui, K., Tomii, K., and Nozaki, T. (2014). Ligand heterogeneity of the cysteine protease binding protein family in the parasitic protist Entamoeba histlytica. Int. J. Parasitol. 44, 625-635. doi: 10.1016/j.ijpara.2014.04.008

McLysaght, A., Baldi, P. F., and Gaut, B. S. (2003). Extensive gene gain associated with adaptive evolution of poxviruses. Proc. Natl. Acad. Sci. U.S.A. 100, 15655-15660. doi: 10.1073/pnas.2136653100

Mirza, H., Teo, J. D., Upcroft, J., and Tan, K. S. (2011a). A rapid, highthroughput viability assay for Blastocystis spp. reveals metronidazole resistance and extensive subtype-dependent variations in drug susceptibilities. Antimicrob. Agents Chemother. 55, 637-648. doi: 10.1128/AAC.00900-10

Mirza, H., Wu, Z., Kidwai, F., and Tan, K. S. (2011b). A metronidazoleresistant isolate of Blastocystis spp. is susceptible to nitric oxide and downregulates intestinal epithelial inducible nitric oxide synthase by a novel parasite survival mechanism. Infect. Immun. 79, 5019-5026. doi: 10.1128/IAI. 05632-11

Mishra, V., Ali, V., Nozaki, T., and Bhakuni, V. (2010). Entamoeba histlytica Phosphoserine aminotransferase (EhPSAT): insights into the structurefunction relationship. BMC Res. Notes 3:52. doi: 10.1186/1756-0500-3-52

Moreno, S. N., and Docampo, R. (1985). Mechanism of toxicity of nitro compounds used in the chemotherapy of trichomoniasis. Environ. Health Perspect. 64, 199-208. doi: 10.1289/ehp.8564199
Müller, J., Ley, S., Felger, I., Hemphill, A., and Müller, N. (2008). Identification of differentially expressed genes in a Giardia lamblia WB C6 clone resistant to nitazoxanide and metronidazole. J. Antimicrob. Chemother. 62, 72-82. doi: $10.1093 / \mathrm{jac} / \mathrm{dkn} 142$

Müller, J., Sterk, M., Hemphill, A., and Müller, N. (2007). Characterization of Giardia lamblia WB C6 clones resistant to nitazoxanide and to metronidazole. J. Antimicrob. Chemother. 60, 280-287. doi: 10.1093/jac/dkm205

Müller, M., and Gorrell, T. E. (1983). Metabolism and metronidazole uptake in Trichomonas vaginalis isolates with different metronidazole susceptibilities. Antimicrob. Agents Chemother. 24, 667-673. doi: 10.1128/AAC.24.5.667

Müller, M., Meingassner, J. G., Miller, W. A., and Ledger, W. J. (1980). Three metronidazole-resistant strains of Trichomonas vaginalis from the United States. Am. J. Obstet. Gynecol. 138, 808-812.

Nakada-Tsukui, K., Tsuboi, K., Furukawa, A., Yamada, Y., and Nozaki, T. (2012). A novel class of cysteine protease receptors that mediate lysosomal transport. Cell. Microbiol. 14, 1299-1317. doi: 10.1111/j.1462-5822.2012.01800.x

Nakada-Tsukui, K., Saito-Nakano, Y., Ali, V., and Nozaki, T. (2005). A retromerlike complex is a novel Rab7 effector that is involved in the transport of the virulence factor cysteine protease in the enteric protozoan parasite Entamoeba histlytica. Mol. Biol. Cell 16, 5294-5303. doi: 10.1091/mbc.E0504-0283

Narcisi, E. M., and Secor, W. E. (1996). In vitro effect of tinidazole and furazolidone on metronidazole-resistant Trichomonas vaginalis. Antimicrob. Agents Chemother. 40, 1121-1125.

Nguewa, P. A., Fuertes, M. A., Cepeda, V., Alonso, C., Quevedo, C., Soto, M., et al. (2006). Poly(ADP-ribose) polymerase-1 inhibitor 3-aminobenzamide enhances apoptosis induction by platinum complexes in cisplatin-resistant tumor cells. Med. Chem. 2, 47-53. doi: 10.2174/157340606775197697

Nozaki, T., Ali, V., and Tokoro, M. (2005). Sulfur-containing amino acid metabolism in parasitic protozoa. Adv. Parasitol. 60, 1-99. doi: 10.1016/S0065$308 \mathrm{X}(05) 60001-2$

Pasupuleti, V., Escobedo, A. A., Deshpande, A., Thota, P., Roman, Y., and Hernandez, A. V. (2014). Efficacy of 5-nitroimidazoles for the treatment of giardiasis: a systematic review of randomized controlled trials. PLoS Negl. Trop. Dis. 8:e2733. doi: 10.1371/journal.pntd.0002733

Pearson, K. (1901). On lines and planes of closest fit to systems of points in space. Philos. Mag. 2, 559-572. doi: 10.1080/14786440109462720

Peláez, T., Cercenado, E., Alcalá, L., Marín, M., Martín-López, A., MartínezAlarcón, J., et al. (2008). Metronidazole resistance in Clostridium difficile is heterogeneous. J. Clin. Microbiol. 46, 3028-3032. doi: 10.1128/JCM.00 524-08

Penuliar, G. M., Furukawa, A., Nakada-Tsukui, K., Husain, A., Sato, D., and Nozaki, T. (2012). Transcriptional and functional analysis of trifluoromethionine resistance in Entamoeba histlytica. J. Antimicrob. Chemother. 67, 375-386. doi: 10.1093/jac/dkr484

Penuliar, G. M., Furukawa, A., Sato, D., and Nozaki, T. (2011). Mechanism of trifluoromethionine resistance in Entamoeba histlytica. J. Antimicrob. Chemother. 66, 2045-2052. doi: 10.1093/jac/dkr238

Plaitakis, A., and Zaganas, I. (2001). Regulation of human glutamate dehydrogenases: implications for glutamate, ammonia and energy metabolism in brain. J. Neurosci. Res. 66, 899-908. doi: 10.1002/jnr.10054

Pumbwe, L., Chang, A., Smith, R. L., and Wexler, H. M. (2007). BmeRABC5 is a multidrug efflux system that can confer metronidazole resistance in Bacteroides fragilis. Microb. Drug Resist. 13, 96-101. doi: 10.1089/mdr.2007.719

Quon, D. V., d'Oliveira, C. E., and Johnson, P. J. (1992). Reduced transcription of the ferredoxin gene in metronidazole-resistant Trichomonas vaginalis. Proc. Natl. Acad. Sci. U.S.A. 89, 4402-4406. doi: 10.1073/pnas.89.10.4402

Ralph, E. D., and Clarke, D. A. (1978). Inactivation of metronidazole by anaerobic and aerobic bacteria. Antimicrob. Agents Chemother. 14, 377-383. doi: 10.1128/AAC.14.3.377

Ralph, E. D., Clarke, J. T., Libke, R. D., Luthy, R. P., and Kirby, W. M. (1974). Pharmacokinetics of metronidazole as determined by bioassay. Antimicrob. Agents Chemother. 6, 691-696.

Ramana, K. V. (2011). Aldose reductase: new insights for an old enzyme. Biomol. Concepts 2, 103-114. doi: 10.1515/bmc.2011.002

Rasoloson, D., Vanácová, S., Tomková, E., Rázga, J., Hrdy, I., Tachezý, J., et al. (2002). Mechanisms of in vitro development of resistance to metronidazole in Trichomonas vaginalis. Microbiology 148, 2467-2477. 
Ravdin, J. I., Murphy, C. F., Salata, R. A., Guerrant, R. L., and Hewlett, E. L. (1985). N-Acetyl-D-galactosamine-inhibitable adherence lectin of Entamoeba histlytica. I. Partial purification and relation to amoebic virulence in vitro. J. Infect. Dis. 151, 804-815.

Reuber, T. L., and Ausubel, F. M. (1996). Isolation of Arabidopsis genes that differentiate between resistance responses mediated by the RPS2 and RPM1 disease resistance genes. Plant Cell 8, 241-249.

Richards, R. G., Sowers, L. C., Laszlo, J., and Sedwick, W. D. (1984). The occurrence and consequences of deoxyuridine in DNA. Adv. Enzyme Regul. 22, 157-185. doi: 10.1016/0065-2571(84)90013-X

Samarawickrema, N. A., Brown, D. M., Upcroft, J. A., Thammapalerd, N., and Upcroft, P. (1997). Involvement of superoxide dismutase and pyruvate:ferredoxin oxidoreductase in mechanisms of metronidazole resistance in Entamoeba histlytica. J. Antimicrob. Chemother. 40, 833-840.

Samuelson, J. (1999). Why metronidazole is active against both bacteria and parasites. Antimicrob. Agents Chemother. 43, 1533-1541.

Sato, D., Nakada-Tsukui, K., Okada, M., and Nozaki, T. (2006). Two cysteine protease inhibitors, EhICP1 and 2, localized in distinct compartments, negatively regulate secretion in Entamoeba histlytica. FEBS Lett. 580, 5306-5312. doi: 10.1016/j.febslet.2006.08.081

Shain, K. H., and Dalton, W. S. (2001). Cell adhesion is a key determinant in de novo multidrug resistance (MDR): new targets for the prevention of acquired MDR. Mol. Cancer Ther. 1, 69-78.

Sharma, A., Sojar, H. T., Glurich, I., Honma, K., Kuramitsu, H. K., and Genco, R. J. (1998). Cloning, expression, and sequencing of a cell surface antigen containing a leucine-rich repeat motif from Bacteroides forsythus ATCC 43037. Infect. Immun. 66, 5703-5710.

Sirinek, K. R. (2000). Diagnosis and treatment of intra-abdominal abscesses. Surg. Infect. (Larchmt) 1, 31-38. doi: 10.1089/109629600321272

Sisson, G., Jeong, J. Y., Goodwin, A., Bryden, L., Rossler, N., Lim-Morrison, S., et al. (2000). Metronidazole activation is mutagenic and causes DNA fragmentation in Helicobacter pylori and in Escherichia coli containing a cloned H. pylori $\mathrm{RdxA}(+)$ (Nitroreductase) gene. J. Bacteriol. 182, 5091-5096. doi: 10.1128/JB.182.18.5091-5096.2000

Smith, M. A., and Edwards, D. I. (1995). Redox potential and oxygen concentration as factors in the susceptibility of Helicobacter pylori to nitroheterocyclic drugs. J. Antimicrob. Chemother. 35, 751-764. doi: 10.1093/jac/35.6.751

Stigler, S. M. (1989). Francis galton's account of the invention of correlation. Stat. Sci. 4, 73-79 doi: 10.1214/ss/1177012580

Tabatabaie, L., Klomp, L. W., Berger, R., and de Koning, T. J. (2010). L-serine synthesis in the central nervous system: a review on serine deficiency disorders. Mol. Genet. Metab. 99, 256-262. doi: 10.1016/j.ymgme.2009.10.012

Tanih, N. F., Ndip, L. M., and Ndip, R. N. (2011). Characterisation of the genes encoding resistance to metronidazole ( $\mathrm{rdxA}$ and frxA) and clarithromycin (the 23S-rRNA genes) in South African isolates of Helicobacter pylori. Ann. Trop. Med. Parasitol. 105, 251-259. doi: 10.1179/136485911X1289983 8683485

Tazreiter, M., Leitsch, D., Hatzenbichler, E., Mair-Scorpio, G. E., Steinborn, R., Schreiber, M., et al. (2008). Entamoeba histlytica: response of the parasite to metronidazole challenge on the levels of mRNA and protein expression. Exp. Parasitol. 120, 403-410. doi: 10.1016/j.exppara.2008.09.011

Tejman-Yarden, N., Millman, M., Lauwaet, T., Davids, B. J., Gillin, F. D., Dunn, L., et al. (2011). Impaired parasite attachment as fitness cost of metronidazole resistance in Giardia lamblia. Antimicrob. Agents Chemother. 55, 4643-4651. doi: 10.1128/AAC.00384-11
Tillack, M., Biller, L., Irmer, H., Freitas, M., Gomes, M. A., Tannich, E., et al. (2007). The Entamoeba histolytica genome: primary structure and expression of proteolytic enzymes. BMC Genomics 8:170. doi: 10.1186/1471-2164-8-170

Townson, S. M., Laqua, H., Upcroft, P., Boreham, P. F., and Upcroft, J. A. (1992). Induction of metronidazole and furazolidone resistance in Giardia. Trans. $R$. Soc. Trop. Med. Hyg. 86, 521-522. doi: 10.1016/0035-9203(92)90095-T

Tukey, J. W. (1949). Comparing individual means in the analysis of variance. Biometrics 5, 99-114. doi: 10.2307/3001913

Upcroft, J. A., and Upcroft, P. (1993). Drug resistance and Giardia. Parasitol. Today 9, 187-190. doi: 10.1016/0169-4758(93)90144-5

Van Oosten, M. A., Notten, F. J., and Mikx, F. H. (1986). Metronidazole concentrations in human plasma, saliva, and gingival crevice fluid after a single dose. J. Dent. Res. 65, 1420-1423. doi: 10.1177/00220345860650120801

Vicente, J. B., Ehrenkaufer, G. M., Saraiva, L. M., Teixeira, M., and Singh, U. (2009). Entamoeba histlytica modulates a complex repertoire of novel genes in response to oxidative and nitrosative stresses: implications for amebic pathogenesis. Cell Microbiol. 11, 51-69. doi: 10.1111/j.1462-5822.2008.01236.x

Wassmann, C., Hellberg, A., Tannich, E., and Bruchhaus, I. (1999). Metronidazole resistance in the protozoan parasite Entamoeba histlytica is associated with increased expression of iron-containing superoxide dismutase and peroxiredoxin and decreased expression of ferredoxin 1 and flavin reductase. J. Biol. Chem. 274, 26051-26056. doi: 10.1074/jbc.274.37.26051

Welch, B. L. (1947). The generalization of "Student's" problem when several different population variances are involved. Biometrika 34, 28-35. doi: 10.1093/biomet/34.1-2.28

West, S. B., Wislocki, P. G., Fiorentini, K. M., Alvaro, R., Wolf, F. J., and Lu, A. Y. (1982). Drug residue formation from ronidazole, a 5-nitroimidazole. $I$. Characterization of in vitro protein alkylation. Chem. Biol. Interact. 41, 265-279. doi: 10.1016/0009-2797(82)90105-3

World Health Organization Amoebiasis. (1997). WHO/PAHO/UNESCO report. A consultation with experts on amoebiasis. Mexico City, Mexico 28-29 January, 1997. Epidemiol. Bull. 18, 13-4.

Wright, J. M., Webb, R. I., O'Donoghue, P., Upcroft, P., and Upcroft, J. A. (2010). Hydrogenosomes of laboratory-induced metronidazole-resistant Trichomonas vaginalis lines are downsized while those from clinically metronidazole-resistant isolates are not. J. Eukaryot. Microbiol. 57, 171-176. doi: 10.1111/j.1550-7408.2009.00455.x

Yarlett, N., Yarlett, N. C., and Lloyd, D. (1986). Ferredoxin-dependent reduction of nitroimidazole derivatives in drug-resistant and susceptible strains of Trichomonas vaginalis. Biochem. Pharmacol. 35, 1703-1708. doi: 10.1016/00062952(86)90327-8

Yoshikawa, T. T., Miyamoto, S., Chow, A. W., and Guze, L. B. (1974). In vitro resistance of Neisseria gonorrhoeae to metronidazole. Antimicrob. Agents Chemother. 6, 327-329. doi: 10.1128/AAC.6.3.327

Conflict of Interest Statement: The authors declare that the research was conducted in the absence of any commercial or financial relationships that could be construed as a potential conflict of interest.

Copyright (C) 2015 Penuliar, Nakada-Tsukui and Nozaki. This is an open-access article distributed under the terms of the Creative Commons Attribution License (CC $B Y)$. The use, distribution or reproduction in other forums is permitted, provided the original author(s) or licensor are credited and that the original publication in this journal is cited, in accordance with accepted academic practice. No use, distribution or reproduction is permitted which does not comply with these terms. 